Bol. Zool. e Biol. Mar., N.S., n.o 30, pp. 567-612, São Paulo, 1973

\title{
MORFOLOGIA EXTERNA DAS FASES DE DESENVOLVIMENTO DE DIAPTOMUS CORDEROI WRIGHT, 1936 (CRUSTACEA, COPEPODA, CALANOIDA)
}

\author{
MÃRCIA NAVARRO CIPÓLLI * \\ Departamento de Zoologia - Inst. de Biociências USP.
}

\section{RESUMO}

Estudou-se e descreveu-se a morfologia externa dos adultos, copepóditos e larvas de Diaptomus corderoi Wright 1936, copépode límnico plantônico do Brasil. Obtivemos sua criação em laboratório $e$ calculamos o comprimento médio de cada estádio do desenvolvimento.

\section{EXTERNAL MORPHOLOGY OF THE DEVELOPMENTAL STAGES OF DIAPTOMUS CORDEROI WRIGHT, 1936 (CRUSTACEA, COPEPODA, CALANOIDA)}

\section{SUMMARY}

The external morphology of adults, copepodids and larvae of Diaptomus corderoi Wright 1936, a planktonic limnic copepod from Brazil, were studied and described. Its rearing in the laboratory was attempted. The average length of each developmental stage was calculated.

\section{INTRODUÇĀO}

Durante os anos de 1968 a 1970 foram feitas coletas mensais de plâncton em um lago artificial situado no "campus" da Cidade Universitária de São Paulo. Entre os animais coletados, encontrou-se uma única espécie de Copepoda Calanoida pertencente ao gênero Diaptomus, cuja criação foi tentada com a finalidade de se descrever suas fases de desenvolvimento.

* Bolsista da Fundação de Amparo à Pesquisa do Estado de São Paulo. 
Inicialmente acreditou-se que o animal encontrado constituia uma espécie nova por não ter sido encontrada na literatura, nenhuma descrição de espécie de Diaptomus que apresentasse todas as características deste. No entanto, assemelhava-se muito a Diaptomus corderoi Wright 1936 que foi coletado na Lagoa Santa situada a cerca de 50 $\mathrm{km}$ ao norte de Belo Horizonte, em 1935.

Para confirmar ou não se era uma espécie nova, 10 fêmeas e 10 machos foram enviados ao Prof. Dr. Friedrich Kiefer que, gentilmente, o identificou como D. (Notodiaptomus) corderoi, apesar de possuir certos caracteres não assinalados na descrição incompleta de Wright. Por isso, será aqui feita a descrição de suas fases de desenvolvimento e uma caracterização mais detalhada da forma adulta da fêmea e do macho.

São inúmeros os trabalhos sobre Calanoida de água doce da América do Sul (Brehm, 1933 c, d; Pearse, 1915, 1921; Wright, 1927, 1935, 1936; etc.). Esses trabalhos são principalmente de sistemática e distribuição geográfica. Wright foi quem mais trabalhou com espécies de Diaptomus do Brasil. Publicações sobre Diaptomus de outras localidades são de Brehm (1933, a, b, c), Dussart (1967), Gurney (1931), Kiefer (1932), Light (1938, 1939), Marques (1966), Marsh (1913, 1915, 1919, 1929), Osorio Taffal (1942), Pennak (1953) e Wilson (1959) cujos trabalhos são muito úteis na identificação de calanoides. Destes, porém, nenhum tratou das fases de desenvolvimento de Calanoida limnicos brasileiros.

Durante o desenvolvimento, a maioria dos copépodes apresenta cinco a seis fases (delimitadas por mudas) naupliares e cinco de copepóditos, sofrendo a última destes, muda para o estádio adulto.

Embora se conheça a estrutura geral dos estádios larvários de copépodes de água doce (Gurney, 1931; Wilson, 1959) poucos estudos detalhados (Comita et al., 1960; Kamal e Armitage, 1967) têm sido feitos sobre a morfologia das fases de desenvolvimento de copépodes calanóides de água doce. Neste trabalho apresentam-se o estudo completo da anatomia externa dos náuplios de $D$. corderoi e a caracterização dos copepóditos por seu aspecto geral, antênulas e patas natatórias. A descrição de cada fase é acompanhada por seu comprimento médio. 


\section{MATERIAIS E MÉTODOS}

O plâncton era coletado com rede de "nylon" com malhă de $60 \mu \mathrm{m}$ de abetura. Após a coleta, o material era levado para o laboratório onde fêmeas ovadas eram colocadas em placas de Petri de $5 \mathrm{~cm}$ de largura por $2 \mathrm{~cm}$ de altura, com água e vegetação do próprio lago. Assim preparadas, as placas eram colocadas em outra maior contendo água a fim de manter-se a temperatura o mais constante possível. Como alimento, colocavam-se algas verdes unicelulares quase todos os dias.

Era obtido o desenvolvimento dos ovos só até a segunda ou terceira fase naupliar e as exúvias não foram encontradas, talvez por terem sido comidas pela fêmea.

Tentou-se então colocar a fêmea ovada em borel de $8 \mathrm{~cm}$ de altura e de $4 \mathrm{~cm}$ de diâmetro contendo água do lago e acrescentando-se alimento quase que diariamente. Assim conseguiu-se o desenvolvimento do ovo até fases mais avançadas. Porém eram poucos os que chegavam ao estádio adulto provavelmente por falta de água fresca do local de coleta. Esta mudança do recipiente de criação favoreceu o desenvolvimento talvez pelo fato de o animal precisar movimentar-se no sentido vertical mais que no horizontal o que não acontece com a maioria dos ciclopóides e harpacticóides. Ainda assim não foram encontradas as exúvias. Desta forma, passou-se a separar, de material fixado com formalina neutra $4 \%$, as fases coletadas com o plâncton. O material então obtido era colocado em solução de $\mathrm{NaOH}$ durante 4 dias aproximadamente, para tornar-se mais transparente. Assim preparados, os animais eram colocados entre lâmina e lamínula e desenhados no microscópio monocular, Leitz, com auxílio de câmara clara Zeiss.

Para se desenhar tanto o aspecto geral do animal como o de seus apêndices, estes eram colocados em uma gota do próprio fixador com pó de vidro ou de quartzo para que não fossem comprimidos quando se colocasse a lamínula. Para a obtenção dos apêndices os animais eram dissecados em glicerina, à lupa, com agulha fina.

Os comprimentos médios das fases foram obtidos medindo-se 50 exemplares cujas dimensões maiores eram projetadas, por meio de câmara clara em folha de papel. Posteriormente os comprimentos eram comparados com uma regua de $1 \mathrm{~mm}$ projetada com o mesmo aumento usado para o animal. 


\section{RESULTADOS}

\section{Descrição das formas adultas}

\section{A - Caracteristicas próprias da fêmea}

50 fêmeas foram medidas. A média destas medidas é 1,206 mm.

A fêmea descrita abaixo tem as seguintes medidas: comprimento total - 1,30 $\mathrm{mm}$; comprimento do céfalo-tórax - 1,0 $\mathrm{mm}$; comprimento do abdome + furca $-0,30 \mathrm{~mm}$; comprimento das antênulas $--1,67 \mathrm{~mm}$.

Céfalo-tórax (Prancha 1, Figs. 1 e 2) : com cinco segmentos torácicos distintos. O quarto segmento torácico apresenta uma protuberância dorsal próximo ao terceiro segmento e o quinto, um espinho de cada lado. Abdome (Prancha 2, Fig. 1): com dois segmentos, sendo o primeiro (genital) levemente assimétrico e expandido dos lados, na região mais próxima do último segmento torácico, com um espinho em cada expansão. O segundo segmento abdominal é reduzido a um terço do comprimento do genital. Antênula (Prancha 3, Fig. 1) : com 25 artículos. Convenções usadas: $\mathrm{s}=$ cerda, $\mathrm{sp}=$ espinho; $\mathrm{a}=$ esteto (de acordo com Wilson, 1959). Setação: $S$, a: $3 \mathrm{~S}$, a: S, a: S: S, a: S, sp: 2 S, a: S: S:S, sp, a: S: S: S: S, a: S: S: S: S, a: S: 2S: $2 \mathrm{~S}$ : 2S: 2S: 3S, a. Quinta pata (Prancha 2, Fig. 5): primeiro artículo basal com um espinho no lado posterior; margem externa do segundo artículo com uma cerda que alcança o meio do primeiro artículo do exopódito; segundo artículo do exopódito com um pequeno espinho lateral externo; terceiro artículo do exopódito, reduzido e com dois espinhos apicais, sendo que o externo é curto e o outro, duas vezes maior. A extremidade do segundo artículo apresenta duas fileiras de cérdulas ou espinhos.

\section{LISTA DAS PRANCHAS}

PRANCHA 1

Fig. 1 - Vista lateral da fêmea; Fig. 2 - Vista dorsal da fêmea; Fig 3 - Vista dorsal da fêmea com saco ovígero; Fig. 4 - Vista lateral do terceiro, quarto e quinto segmentos torácicos, abdome e saco ovígero; Fig. 5 - Vista dorsal do último segmento torácico, abdome e saco ovígero. Nota: $\mathrm{Na}$ fig. 1 não foram representados os apêndices. 


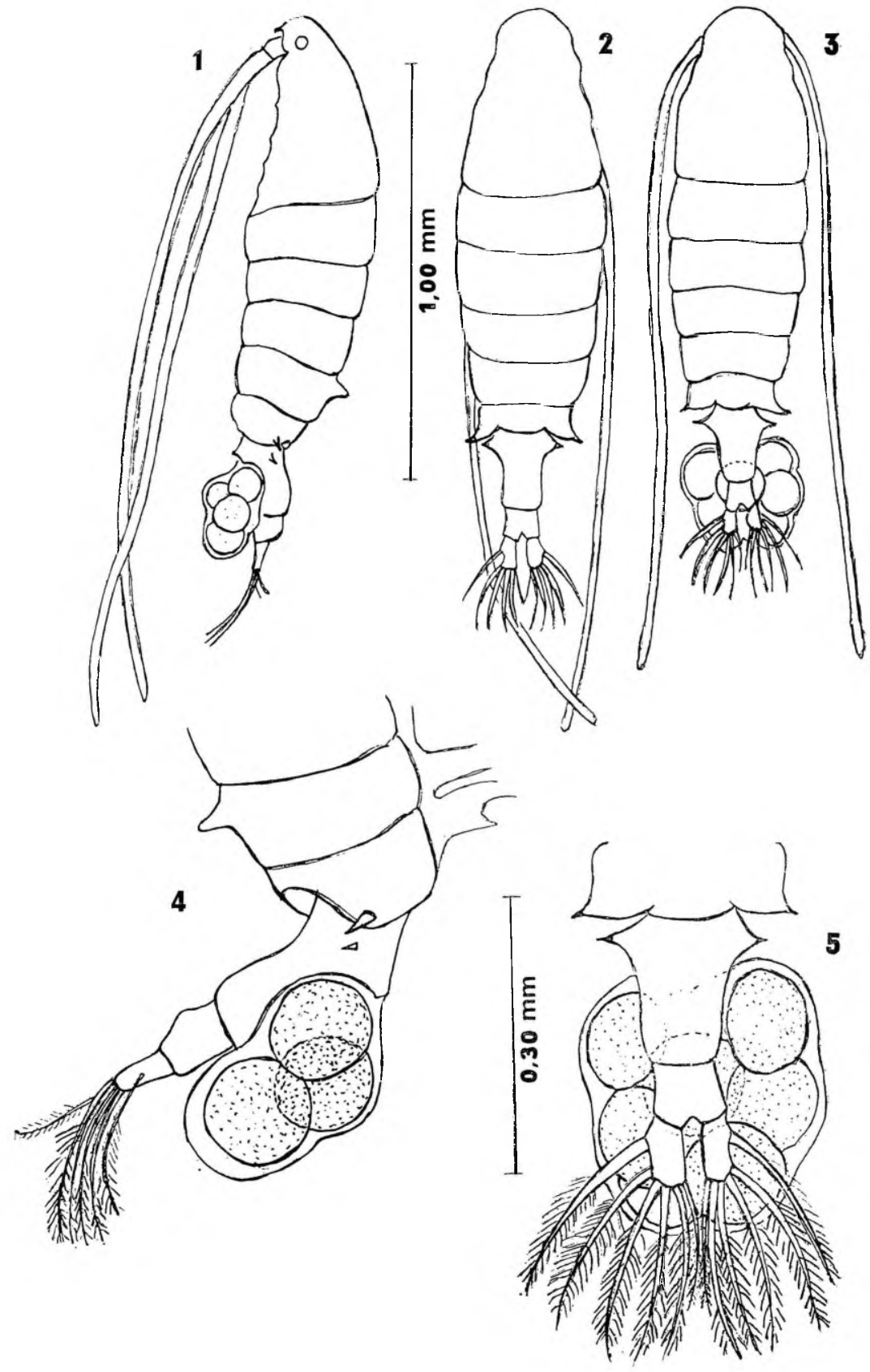

2 RA N C HA 2 


\section{B - Características próprias do macho}

A média dos comprimentos de 50 exemplares foi $1,066 \mathrm{~mm}$.

O macho descrito abaixo apresenta as seguintes medidas: comprimento total - $1,0 \mathrm{~mm}$; comprimento do céfalo-tórax $-0,67 \mathrm{~mm}$;

comprimento da antênula esquerda - 1,1 mm; comprimento da antênula direita $-1,15 \mathrm{~mm}$.

Céfalo-tórax (Prancha 3, Figs. 2 e 3) : com cinco segmentos torácicos, tendo o quinto um espinho de cada lado mas menos desenvolvido que na fêmea. Abdome (Prancha 3, Fig. 3): com cinco segmentos. Antênula direita (Prancha 3, Fig. 4) : geniculada e com 23 artículos. Antênula esquerda (Prancha 3, Fig. 1) : não geniculada e com 25 artículos. Quanto à distribuição de cerdas é igual à da fêmea mas difere com respeito à base e região de implantação que são mais desenvolvidas. Quinto par de patas (Prancha 3, Fig. 5). Pata direita (Prancha 3, Fig. 5 D) : Região posterior do primeiro artículo basal com uma proeminência mamelar em cuja ponta há um espinho; segundo artículo basal com uma cerda lateral na margem externa, próximo ao primeiro artículo do exopódito, e três pequenas saliências laterais internas; segundo artículo do exopódito com longo gancho terminal recurvado na direção da pata esquerda e apresentando uma fileira de cerdas curtas e fortes; endopódito uni-articulado com um comprimento igual a $2 / 5$ do primeiro artículo do exopódito, dois fortes espinhos e uma fileira de cerdas curtas. Pata esquerda (Prancha 3, Fig. 5 E) : Não alcança e extremidade do primeiro artículo do exopódito da pata direita; região posterior do primeiro artículo basal com um espinho em uma pequena proeminência; o segundo artículo basal apresenta uma reentrância distal externa, de onde sai uma cerda; a região distal do exopódito apresenta-se pontiaguda com um espinho na margem interna e, abaixo, uma proeminência cerdosa. O espinho interno possui outro menor na extremidade. O artículo proximal do exopódito tem em sua

\section{PRANCHA 2}

Fig. 1 - Vista dorsal do último segmento torácico e abdome da fêmea; Fig. 2 Primeiro segmento abdominal da fêmea mostrando detalhe do orifício genital; Fig. 3 - Vista ventral do primeiro segmento abdominal com saco ovígero; Fig. 4 - Vista lateral do abdome da fêmea com dois espermatóforos presos ao orifício genital; Fig. 5 - Vista posterior do quinto par de patas da fêmea. 

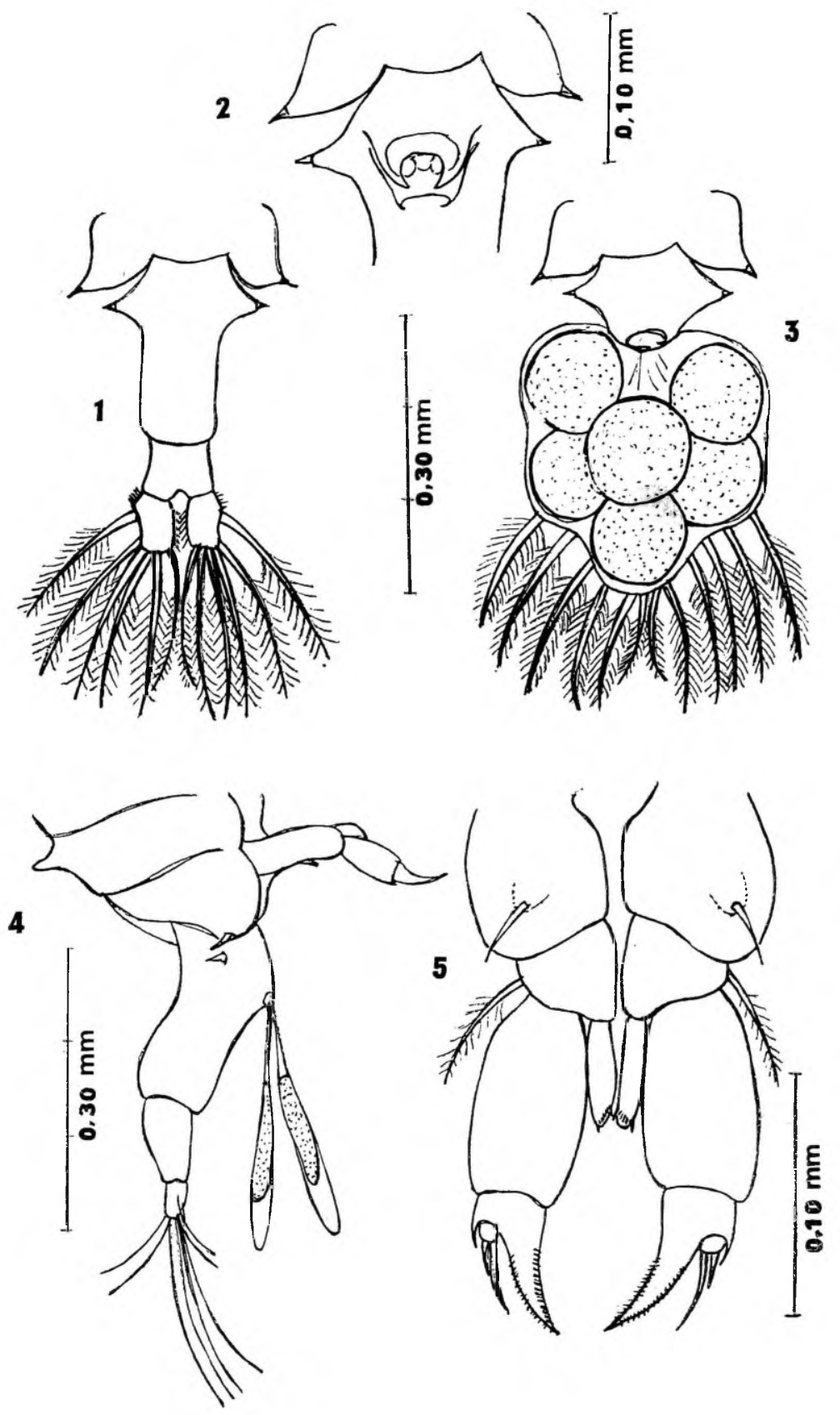
margem interna uma proeminência digitiforme com cerdas curtas. $\mathrm{O}$ endopódito alcança a articulação do primeiro artículo do exopódito e apresenta a extremidade pontiaguda com uma coroa de cérdulas préterminal e um espinho pequeno do lado interno.

$\mathrm{C}$-Caracteres comuns ao macho e à fêmea

São as antenas, mandíbulas, maxílulas, maxilas, maxilípedes e patas I-IV representadas respectivamente pelas figuras: 1 (Prancha 4), 5 (Prancha 4), 2 (Prancha 4), 3 (Prancha 4), 4 (Prancha 5), 2 (Prancha 5), 3 (Prancha 5) e 4 (Prancha 5).

\section{Descricão das formas larvais}

A - Descrição das fases naupliares

A fêmea de $D$. corderoi carrega de 4 a 7 ovos no saco ovígero. Esses ovos apresentam cor acinzentada e um diâmetro de $100 \mu \mathrm{m}$ aproximadamente.

\section{Náuplio I}

50 animais medidos apresentaram um comprimento médio igual a $145 \mu \mathrm{m}$.

Corpo (Pranchas 6 e 7, Fig. 1) de forma ovalada com três pares de apêndices e duas cerdas furcais situadas em um mesmo plano. Lábio superior bem desenvolvido em relação ao tamanho do corpo.

Antênula (Prancha 8, Fig. 1) : com 3 artículos - 1.० artículo pequeno em relação ao segundo e sem cerdas ou qualquer outra estrutura; $2 .^{\circ}$ artículo, longo e com três cerdas de comprimentos quase iguais; $3 .^{\circ}$ artículo com três cerdas apicais mais longas que o artículo no qual se inserem.

Antena (Pr. 8, Fig. 7) : com coxa, base, endopódito e exopódito. Coxa: com protuberância interna em que se insere uma longa cerda.

\section{PRANCHA 3}

Fig. 1 - Antênula da fêmea (= antênula esquerda do macho); Fig. 2 - Vista lateral do macho; Fig. 3 - Vista dorsal dos últimos segmentos torácicos e abdome do macho; Fig. 4 - Antênula direita do macho; Fig. 5E - Vista anterior da quinta pata esquerda do macho; Fig. 5D - Vista anterior da quinta pata direita do macho. Nota: Na fig. 2 não foram representados os apêndices. 

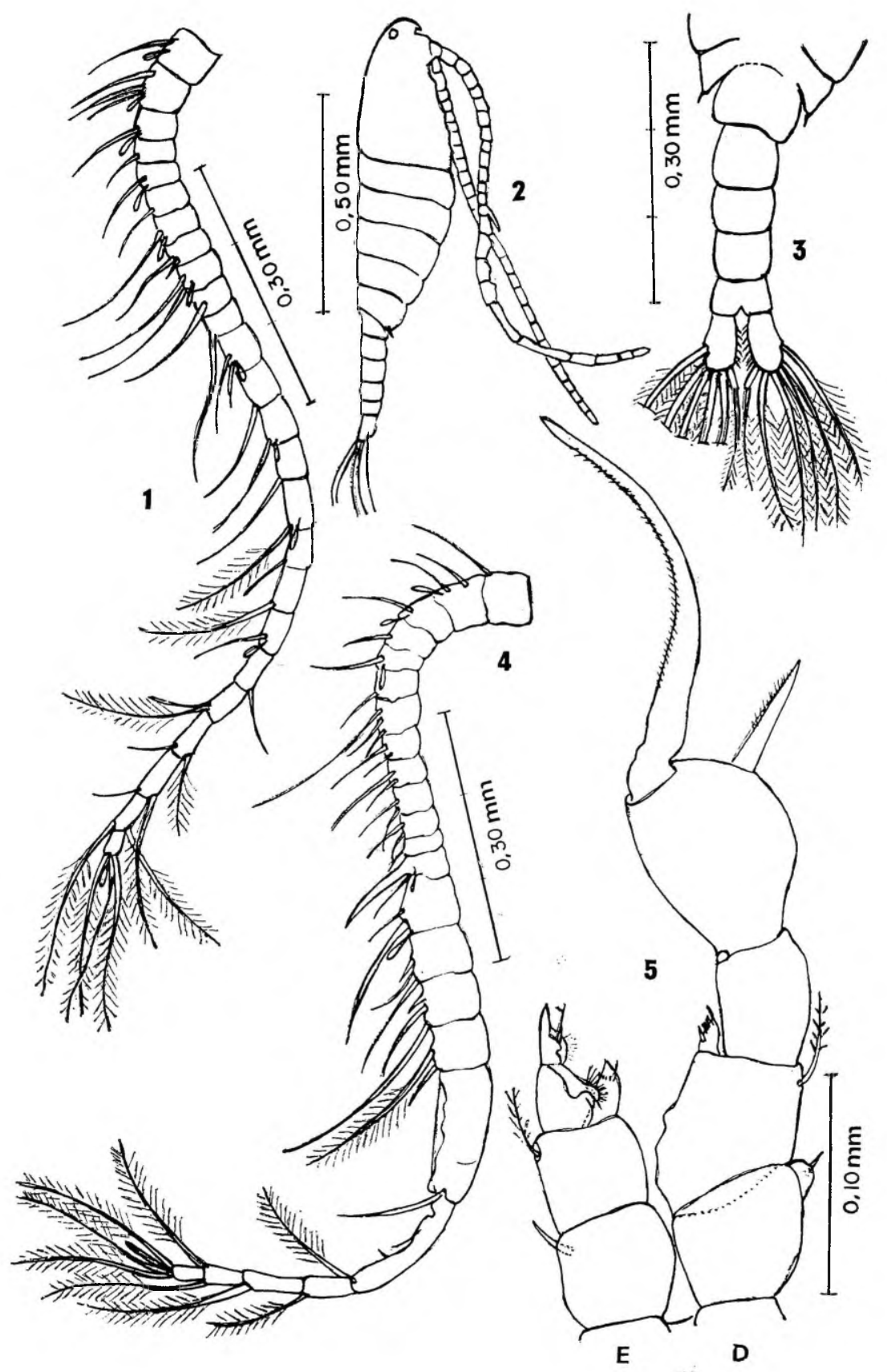

PRA INCHA 3 
Base: com duas longas cerdas. Endopódito: não articulado, com uma cerda lateral interna e duas longas apicais. Exopódito: com 5 artículos, sendo o primeiro maior que a metade do ramo inteiro. Os quatro primeiros artículos com uma longa cerda lateral interna cada e o último com duas cerdas apicais.

Mandíbula (Pr. 8, Fig. 13) : com coxa, base, endopódito e exopódito bem distintos. Coxa: com longa cerda situada em protuberância interna. Base: com duas cerdas laterais internas. Endopódito: com duas cerdas laterais internas, duas sub-apicais e duas longas apicais.

Exopódito: com quatro artículos, tendo os três primeiros uma cerdu cada um e o último duas cerdas de comprimentos diferentes.

\section{Náuplio II}

De 50 animais medidos obteve-se um comprimento médio de $165 \mu \mathrm{m}$.

Corpo (Pranchas 6 e 7, Fig. 2): mais alongado que o do náuplio I mas ainda ovalado. Termina em dois pequenos lobos posteriores furcais, cada um com uma cerda, mais longa que a da fase anterior, sendo a da direita dirigida para a região dorsal. Apresenta três pares de apêndices e três pares de fileiras de cérdulas, situadas ventralmente, que correspondem aos primórdios dos três pares seguintes de apêndices.

Antênula (Pr. 8, Fig. 2) com três artículos. Primeiro artículo como na fase anterior, segundo artículo com três cerdas sendo a primeira (a mais próxima do $1 .^{\circ}$ artículo) bem mais curta que as outras; terceiro artículo com três longas cerdas e 1 esteto, apicais, e uma fileira de cérdulas de cada lado que se iniciam, de um lado, no ponto médio e do outro pouco mais abaixo.

Antena (Pr. 8, Fig. 8) : com coxa, base, endopódito e exopódito bem distintos. Coxa: com uma protuberância com duas grossas cerdas e uma mais fina. Base: com uma cerda grossa e uma fina junto à base e outra fina situada medianamente. Endopódito: não articula-

\section{PRANCHA 4}

Fig. 1 - Antena; Fig. 2 - Maxilula; Fig. 3 - Maxila; Fig. 4 - Maxilipede; Fig. 5 - Mandíbula. Nota: Vários autores usam uma nomenclatura diferente desta para os apêndices cefálicos. A nomenclatura aqui adotada é de Gurney 

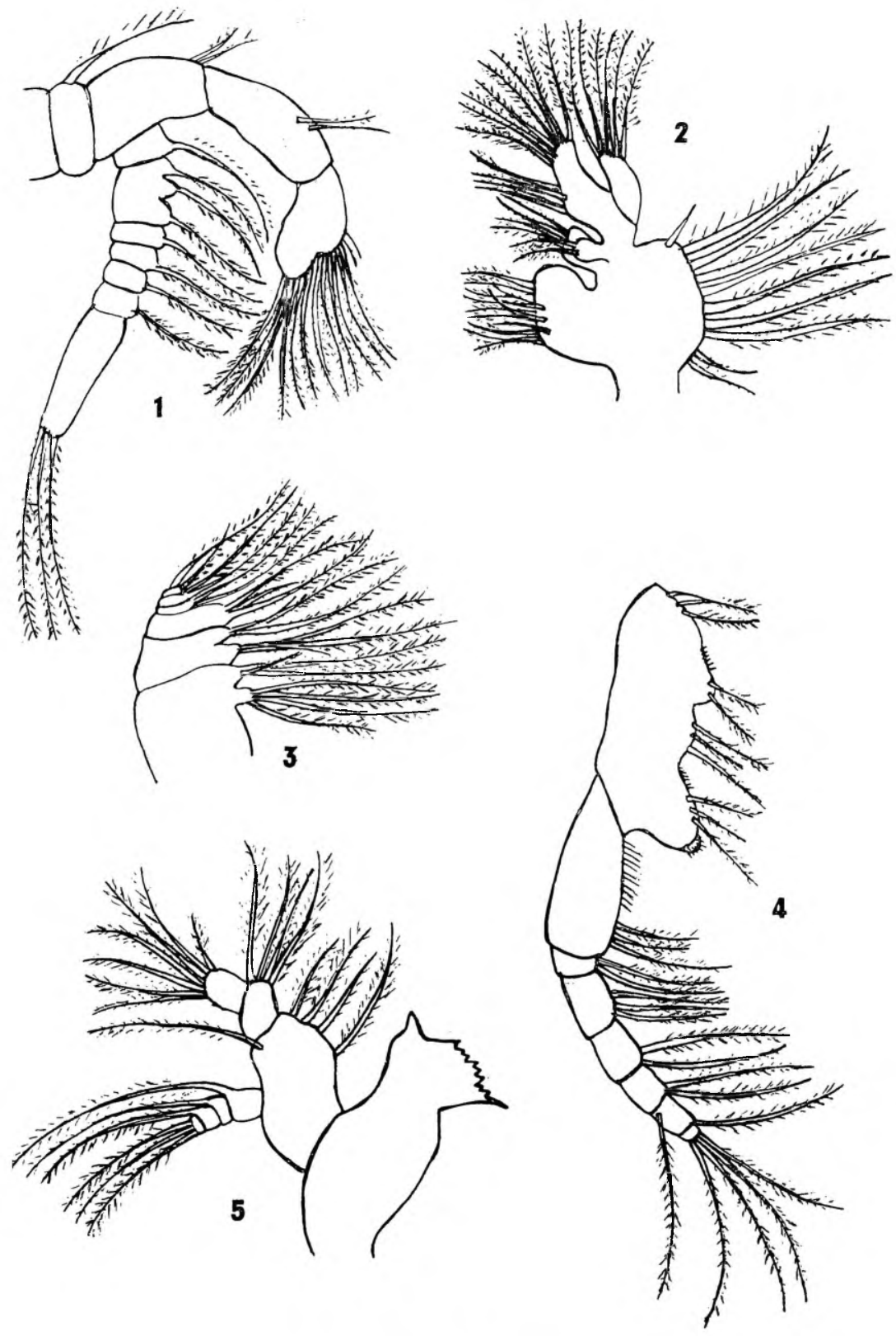

$0.10 \mathrm{~mm}$ 
do, com duas cerdas no lado interno e três apicais. Exopódito: com cinco artículos distintos tendo o primeiro duas longas cerdas internas, os três seguintes uma cerda cada um e o último duas longas apicais.

Mandíbula (Pr. 8, Fig. 14) : com coxa, base, endopódito e exopódito distintos. Coxa: com longa cerda na protuberância. Base: com três cerdas internas sendo mais grossa a situada próximo à base. Endopódito: não articulado mas lobulado; apresenta um grupo de quatro cerdas, duas cerdas mais acima e, no ápice, três cerdas longas. Exopódito: com quatro artículos que apresentam, internamente: o primeiro, duas longas cerdas, os dois seguintes uma cerda cada um e o último, duas cerdas apicais.

\section{Náuplio III}

Medindo-se 50 animais obteve-se um comprimento médio igual a $184 \mu \mathrm{m}$.

Corpo (Prs. 6 e 7, Fig. 3) : mais alongado que nas fases anteriores mas com leve formato de pera e com início de segmentação; lobos furcais desenvolvidos apresentando, cada um, uma cerda grossa e uma mais fina voltada para o dorso, sendo a da direita mais inclinada para o dorso que a da esquerda.

Apresenta três pares de apêndices-antênulas, antenas, mandíbulas - e esboço do quarto, quinto e sexto pares de apêndices: maxílulas (Pr. 6, Fig. $3 \mathrm{~m}$ ') representadas, cada uma, por dois fortes espinhos em uma protuberância posterior à mandíbula; maxilas (Pr. 6, Fig. 3 m"), representadas, cada uma, por um espinho pequeno situado posteriormente à maxílula; maxilípedes (Pr. 6, Fig. $3 \mathrm{mxp}$ ) representados por um grupo de cérdulas cada um.

Antênula (Pr. 8, Fig. 3) : como no náuplio II mas com cinco cerdas - uma lateral, uma sub-apical e 3 apicais - e uma cérdula no terceiro artículo.

Antena (Pr. 8, Fig. 9) : com coxa, base, endopódito e exopódito bem distintos. Coxa: com duas cerdas grossas e uma fina em protuberância interna. Base: com quatro cerdas no lado interno: 3 basais -

PRANCHA 5

Fig. 1 - Primeira pata; Fig. 2 - Segunda pata; Fig. 3 - Terceira pata; Fig. 4 - Quarta pata. 
1

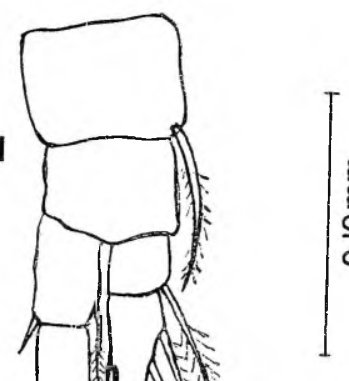

1

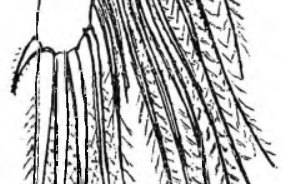

:

(1)

相

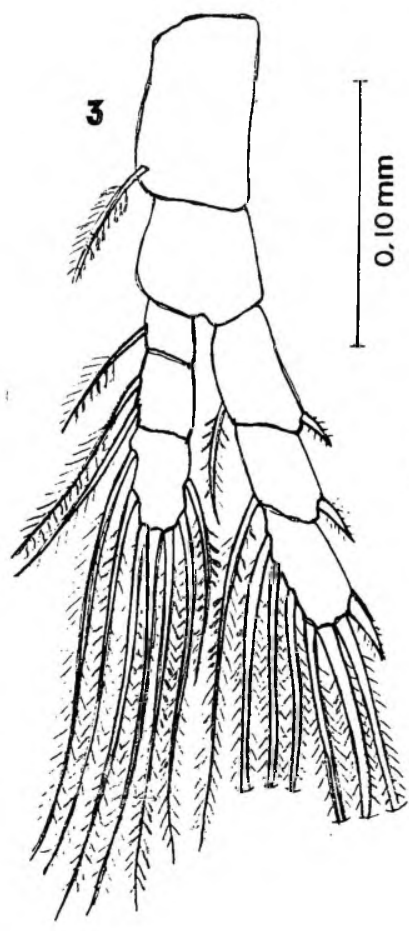

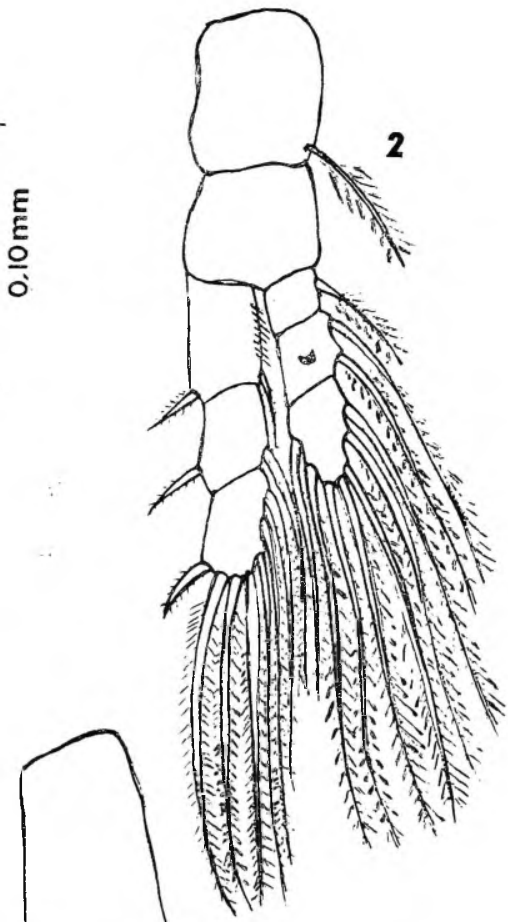
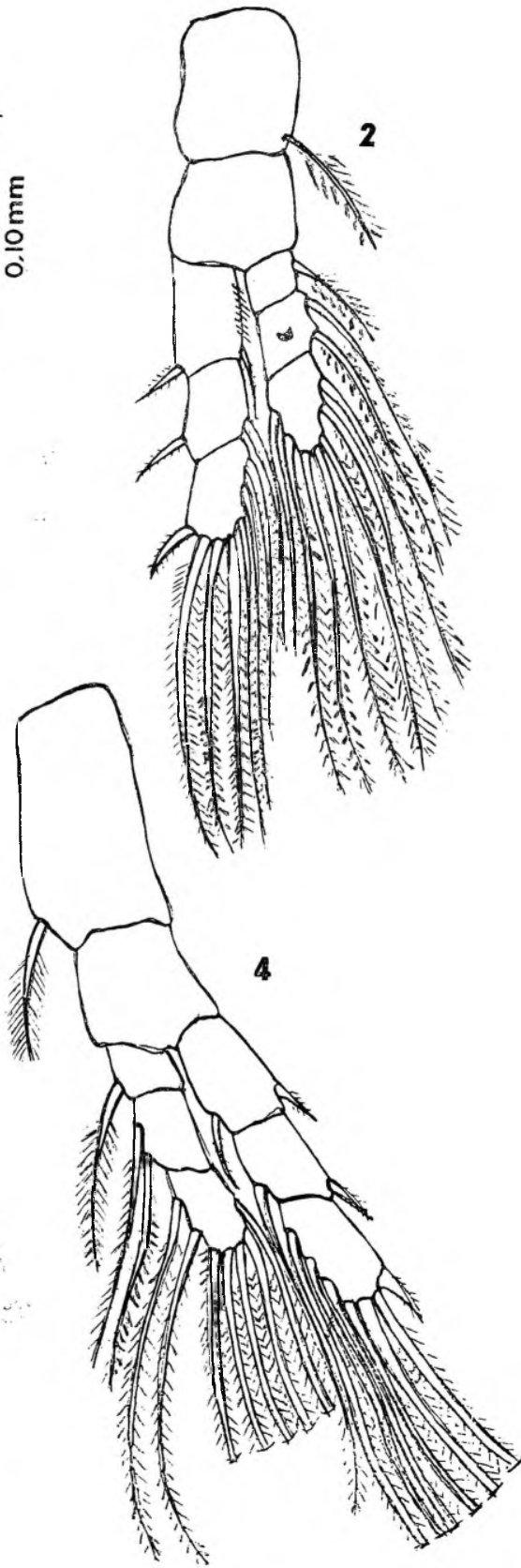
uma delas mais grossa - e uma mediana. Endopódito: não articulado, com três cerdas do lado interno e três apicais. Exopódito: com cinco artículos, tendo o primeiro duas longas cerdas, o segundo, terceiro e quarto, uma cerda e o quinto três longas cerdas: uma subapical e duas apicais.

Mandíbula (Pr. 8, Fig. 15) : com coxa, base, endopódito e exopódito. Coxa: com uma cerda em protuberância interna. Base: com três cerdas internas sendo a mais basal, maior e mais grossa. Endopódito: não articulado, com um grupo de quatro cerdas internas próximo à base, duas mais acima e quatro apicais. Exopódito: com quatro artículos: duas cerdas internas no primeiro, uma cerda nos dois seguintes e duas apicais no último.

\section{Náuplio IV}

Medindo-se 50 náuplios, obteve-se um comprimento médio de 254 $\mu \mathrm{m}$.

Corpo (Prs. 6 e 7, Fig. 4) : bem mais comprido que largo e ainda com forma de pera. Tem os lobos furcais mais desenvolvidos e com duas cerdas cada um, sendo a ventral mais forte que a dorsal. Nesta fase, também, a cerda dorsal direita inclina-se mais para o dorso que a esquerda.

Possui três pares de apêndices — antênulas, antenas, mandíbulas - e esboço dos três seguintes.

Antênula (Pr. 8, Fig. 4): com três artículos: primeiro artículo como na fase anterior; segundo artículo com três cerdas, sendo as duas terminais mais longas que a primeira; terceiro artículo com sete longas cerdas - 3 laterais, duas sub-apicais e 2 apicais - duas cérdulas laterais e um esteto apical.

Antena (Pr. 8, Fig. 10): com coxa, base, endopódito e exopódito. Coxa: com duas cerdas grossas e uma fina em protuberância interna. Base: com quatro cerdas na margem interna: 3 próximo à base e

PRANCHA 6 - Náuplios em vista ventral

Fig. 1 - Náuplio I; Fig. 2 - Náuplio II; Fig. 3 - Náuplio III; Fig. 4 Náuplio IV; Fig. 5 - Náuplio V; Fig. 6 - Náuplio VI. Legendas: m’ = maxílula; $\mathrm{m}$ " = maxila; $\mathrm{mxp}=$ maxilípede; $\mathrm{p} 1=$ pata: $\mathrm{p} 2=$ pata 2 . Nota: Só foi representado um apêndice de cada par. 


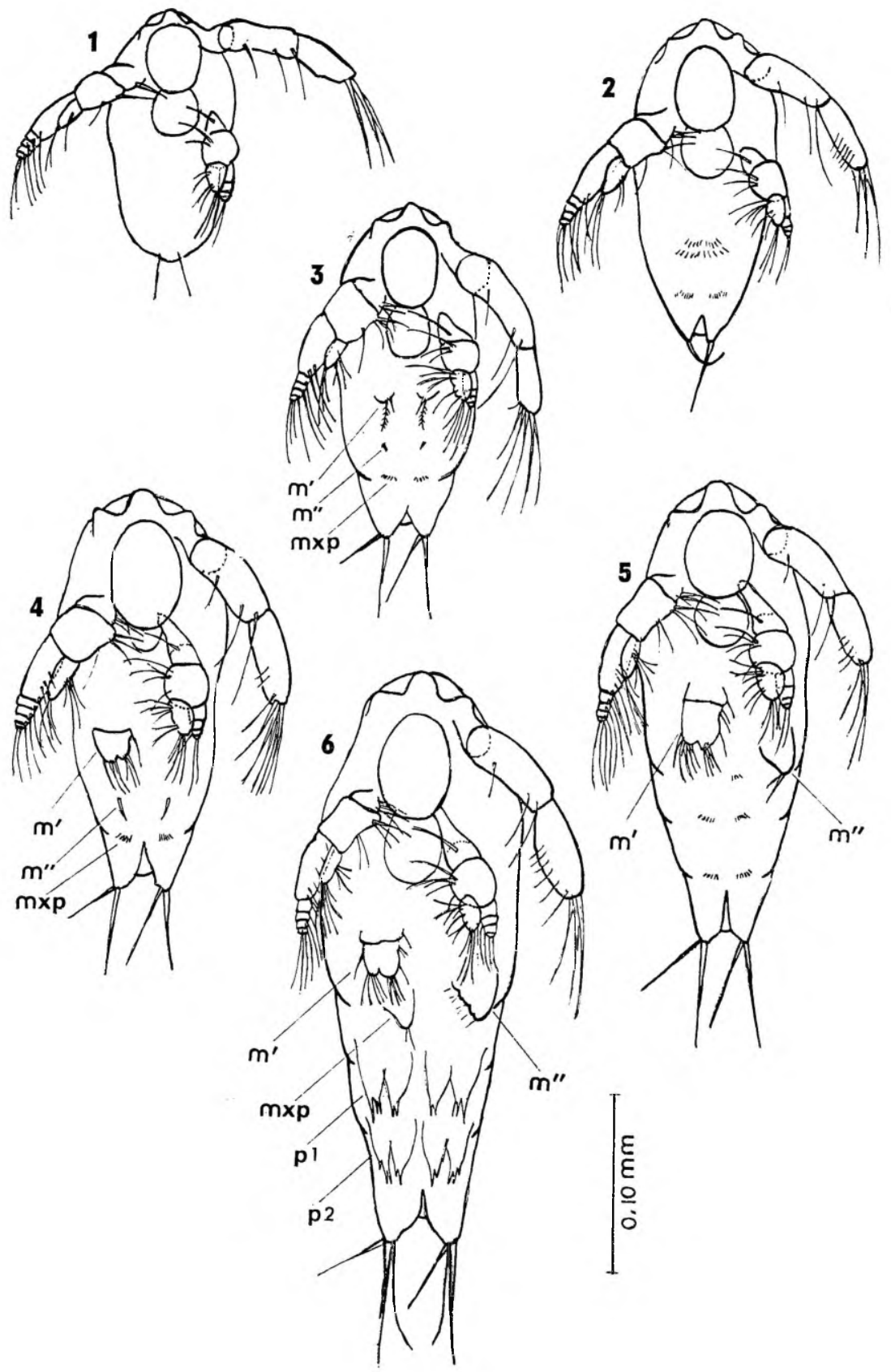

P R A N C HA 6 
1 mediana. Endopódito: não articulado, com três cerdas do lado interno e quatro apicais sendo uma mais curta que as outras três. Exopódito: com cinco artículos: primeiro artículo com duas cerdas curtas e duas longas situadas no lado interno; os três seguintes, cada um, com uma cerda longa e interna e o quinto com três: uma sub-apical e duas apicais.

Mandíbula (Pr. 8, Fig. 16) : com coxa, base, endopódito e exopódito. Coxa: com lâmina mandibular bem desenvolvida apresentando quatro dentes na extremidade e uma longa cerda que parte da base. Base: com cinco cerdas do lado interno: quatro próximas à base e uma mais acima. Endopódito: não articulado, com quatro cerdas no $1 .^{\circ}$ lobo, duas entre o segundo e o terceiro lobo e quatro terminais. Exopódito: com quatro artículos tendo, o primeiro, duas longas cerdas, os dois seguintes, uma cada e o último duas apicais.

Maxílula (Pr. 6, Fig. 4 m') : bilobada, tendo cada lobo três fortes cerdas terminais. O lobo interno possui, também, uma cerda no lado interno junto à base.

Maxila (Pr. 6, Fig. $4 \mathrm{~m}$ "): representada por um único espinho.

Maxilipede (Pr. 6, Fig. $4 \mathrm{mxp}$ ): representado por uma série de cérdulas.

\section{Náuplio V}

De 50 animais medidos, obteve-se um comprimento médio igual a $291 \mu \mathrm{m}$.

Corpo (Prs. 6 e 7, Fig. 5): bastante alongado onde já se notam três inicios de segmentação. Os lobos furcais aparecem, cada um, com duas cerdas sendo a dorsal direita mais inclinada para o dorso que a esquerda. Os três primeiros pares de apêndices são bem desenvolvidos como nas fases anteriores e há esboços dos cinco pares seguintes.

Antênula (Pr. 8, Fig. 5): como na fase anterior apenas quanto aos dois primeiros artículos; terceiro artículo com quatro cérdulas la-

PRANCHA 7 - Náuplios em vista lateral direita

Fig. 1 - Náuplio I; Fig. 2 - Náuplio II; Fig. 3 - Náuplio III; Fig. 4 Náuplio IV; Fig. 5 - Náuplio V; Fig. 6 - Náuplio VI. Nota: os círculos indicam a região de inserção dos três primeiros apêndices. 

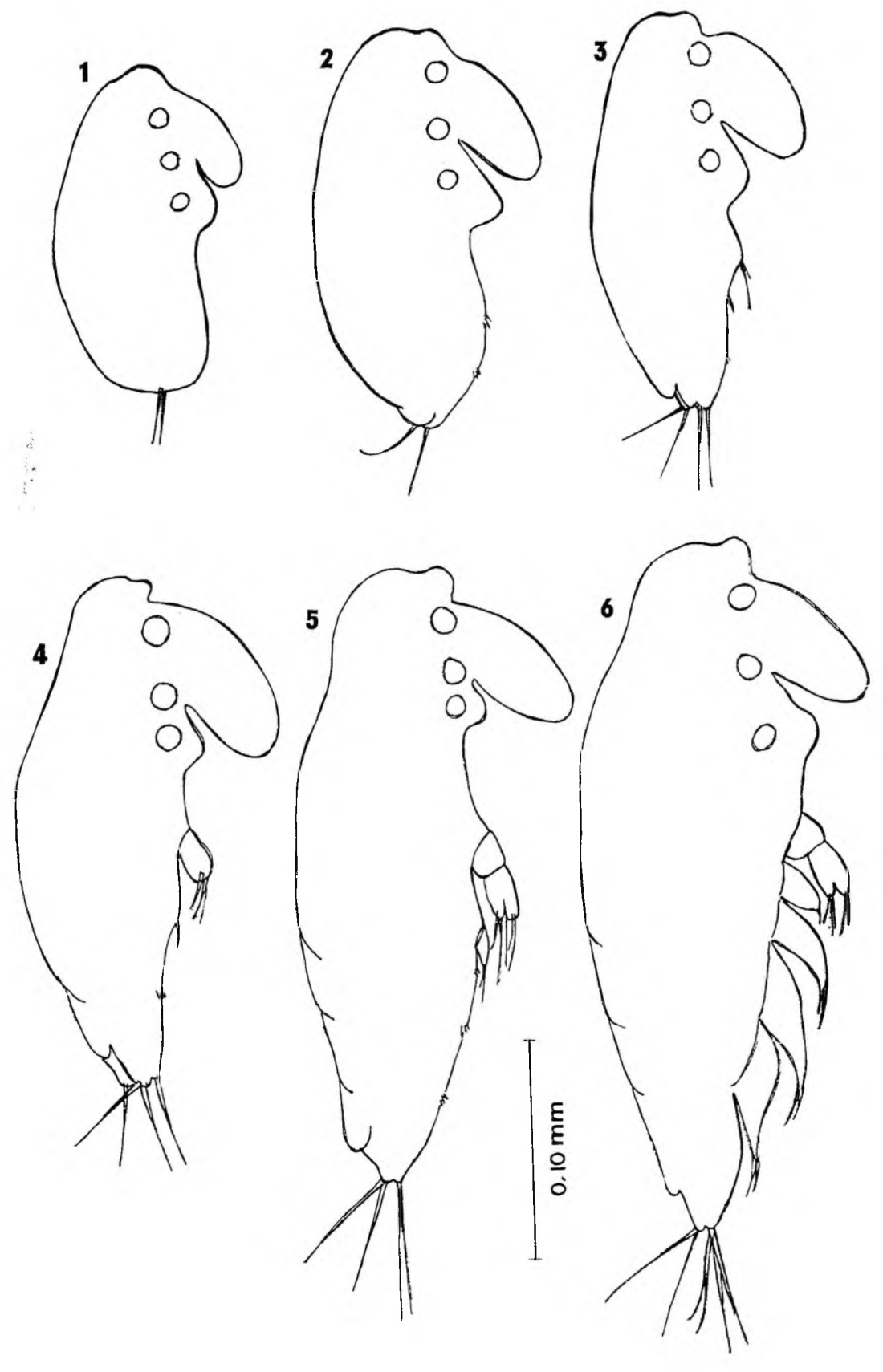

PRA NCHA 7 
terais, nove cerdas longas sub-apicais, apicais e laterais e um esteto apical.

Antena (Pr. 8, Fig. 11) : com as mesmas partes apresentadas pelas fases anteriores. Coxa: com duas grossas cerdas e uma fina, internas. Base: com cinco cerdas internas: três junto à base e duas medianas. Endopódito: não articulado, com quatro cerdas sendo duas curtas e duas pouco maiores situadas lateralmente a quatro cerdas apicais: três longas e uma curta. Exopódito: com cinco artículos: primeiro artículo longo com cinco cerdas: duas longas distais e três curtas mais abaixo; artículos 2, 3 e 4 com uma longa cerda cada um, e o último com três longas cerdas: uma sub-apical e duas apicais.

Mandíbula (Pr. 8, Fig. 17) : com coxa, base, endopódito e exopódito. Coxa: com lâmina mandibular bastante desenvolvida com cinco dentes na extremidade e uma longa cerda na base. Base: com um grupo basal de quatro cerdas internas e uma cerda mais acima. Endopódito: com onze cerdas ao todo e agrupadas, da base para o ápice, do seguinte modo: $4,1,2,4$. Exopódito: com quatro artículos tendo o primeiro duas cerdas, os dois seguintes uma cada e o último duas apicais.

Maxílula (Pr. 6, Fig. 5 m') : com dois artículos: primeiro artículo com uma cerda interna; segundo artículo bilobado: lobo externo com cinco cerdas e interno com 7 cerdas: 4 apicais e três laterais.

Maxila (Pr. 6, Fig. 5 m") : representada por um artículo com dois espinhos na extremidade.

Os três apêndices seguintes, maxilípedes, patas I e II, são representados por fileiras de cérdulas.

\section{Náuplio VI}

Medindo-se 50 exemplares encontrou-se um comprimento médio igual a $345 \mu \mathrm{m}$.

PRANCHA 8 - Apêndices dos náuplios

(A1 = antênula; $\mathrm{A} 2$ = antena; $\mathrm{Md}=$ mandibula)

Fig. $1-A 1$ de N I; Fig. $2-A 1$ de N II; Fig. $3-$ A1 de N III; Fig. $4-A 1$ de N IV; Fig. 5 - A1 de N V; Fig. 6 - A1 de N VI; Fig. 7 - A2 de N I; Fig. 8 A2 de N II; Fig. 9 - A2 de N III; Fig. $10-$ A2 de N IV; Fig. 11 - A2 de N V; Fig. 12 - A2 de N VI; Fig. 13 - Md de N I; Fig. $14-$ Md de N II; Fig. $15-$ Md de N III; Fig. 16 - Md de N IV; Fig. 17 - Md de NV; Fig. 18 - Md de $\mathrm{N}$ VI. (Náuplio I a náuplio $\mathrm{VI}=\mathrm{NI}$ a $\mathrm{N}$ VI). 

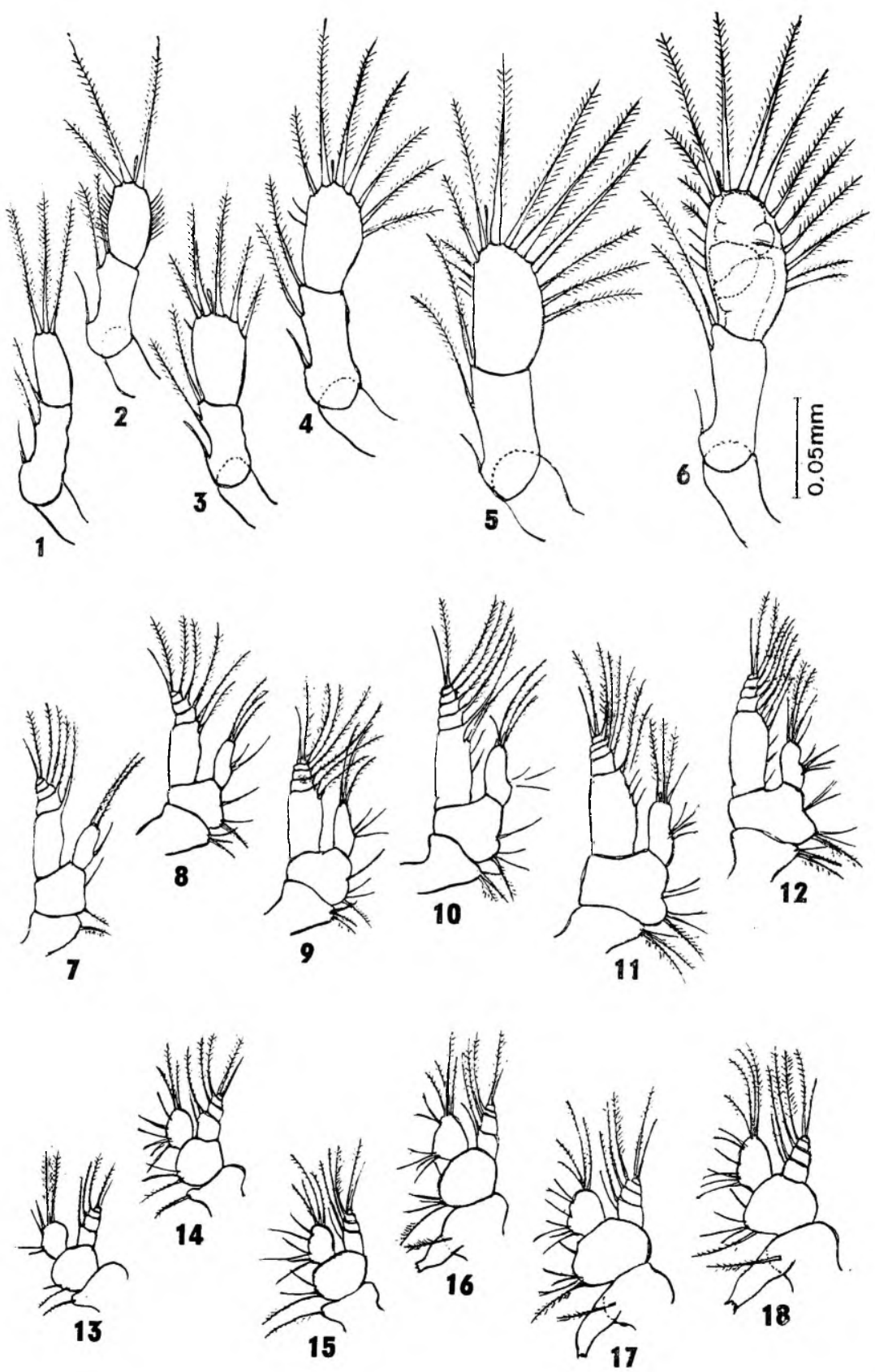
Corpo (Prs. 6 e 7, Fig. 6) : O comprimento é quase três vezes a maior largura. Os lobos furcais, agora mais desenvolvidos, apresentam três cerdas cada um: duas ventrais e uma dorsal sendo a da direita mais inclinada para o dorso que a da esquerda. Entre as ventrais, a interna é menor que a externa e levemente recurvada para o dorso.

Aparecem oito pares de apêndices, alguns bem desenvolvidos e outros rudimentares: os três primeiros com desenvolvimento semelhante ao da fase anterior e os cinco últimos rudimentares, mas mais desenvolvidos que no estádio precedente.

Antênula (Pr. 8, Fig. 6) : com três artículos. Os dois primeiros iguais aos da fase anterior e o terceiro mais longo e alargado apresentando internamente indícios de divisão e possuindo cinco cerdas pequenas de um lado, uma cerda pequena sub-apical, três cerdas longas apicais e cinco longas e duas menores do outro lado. Há também um esteto entre duas cerdas apicais.

Antena (Pr. 8, Fig. 12) : apresenta coxa, base, endopódito e exopódito. Coxa: com protuberância interna na qual se inserem três cerdas: duas grossas e uma fina. Base: com cinco cerdas internas como na fase anterior. Endopódito: não articulado e com quatro cerdas laterais internas, quatro apicais e uma sub-apical. Exopódito: com cinco artículos: o primeiro, longo, com três cerdas longas e três pequenas. Em sua base já se nota início de divisão. Os três artículos seguintes têm uma cerda interna cada e o último duas cerdas apicais e uma sub-apical.

Mandíbula (Pr. 8, Fig. 18) : com coxa, base, endopódito e exopódito. Coxa: com forte lâmina mandibular com 5 dentes na extremidade e uma longa cerda na base. Base: com cinco cerdas internas como na fase anterior. Endopódito: não articulado e com um grupo de quatro cerdas laterais internas, uma mediana, duas mais acima e quatro apicais. Exopódito: com quatro artículos, tendo o primeiro duas longas cerdas internas, os dois seguintes uma cada um e o último duas cerdas apicais.

PRANCHA 9 - Copepóditos em vista lateral

Fig. 1 - Copepódito I; Fig. 2 - Copepódito II; Fig. 3 - Copepódito III; Fig. 4 - Copepódito V ó; Fig. 5 - Copepódito IV; Fig. 6 - Copepódito V 9 . Nota: Não foram representados os apêndices com exceção da antênula e da quinta pata da fêmea na Fig. 6 . 


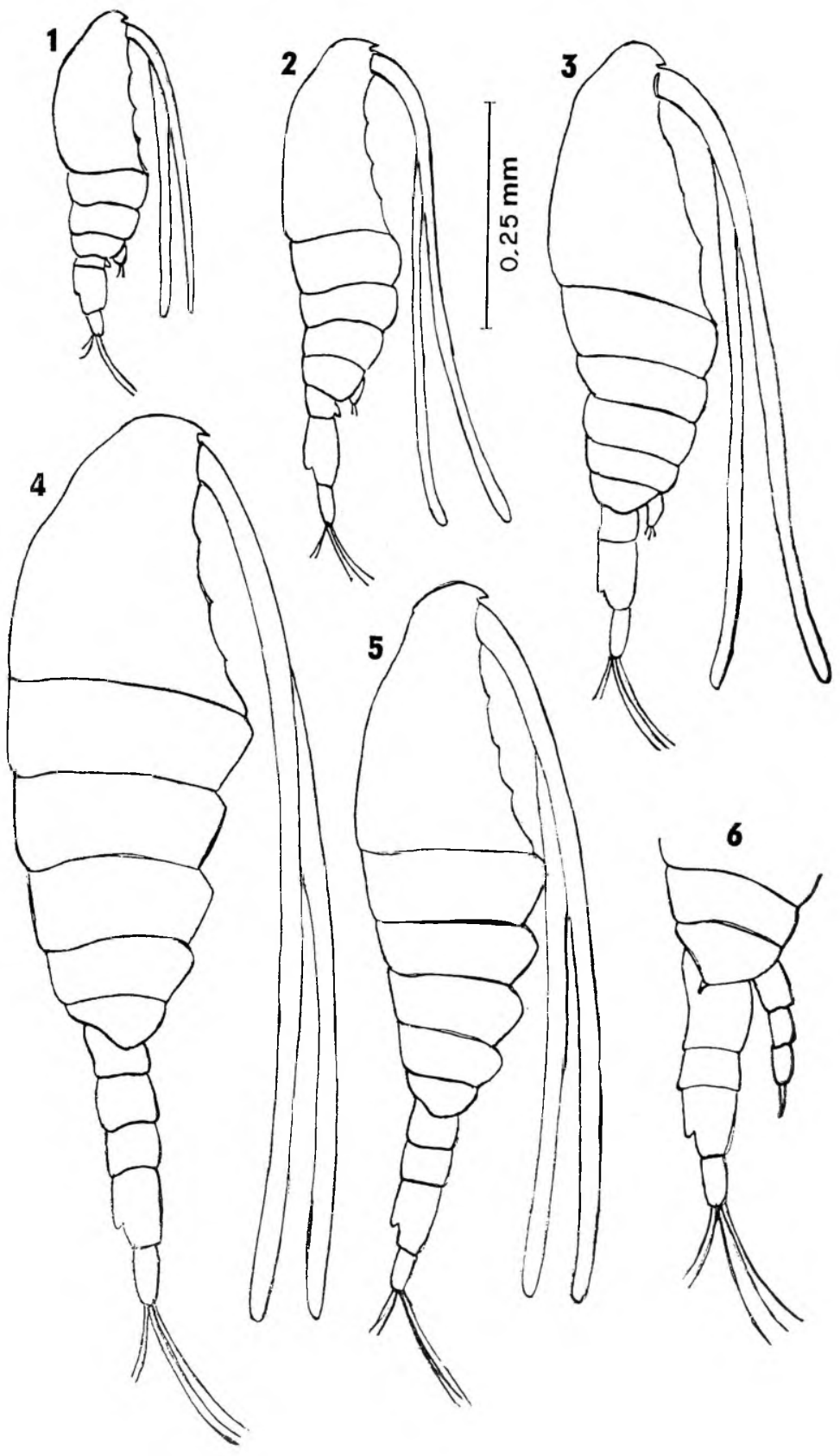


Maxílula (Pr. 6, Fig. 6 m') : com dois artículos: $10^{\circ}$ artículo com uma cerda interna; $2 .^{\circ}$ artículo com três lobos: lobo externo com 6 cerdas: uma lateral e cinco terminais; lobo interno distal com quatro cerdas terminais e uma lateral, lobo interno basal com duas cerdas curtas.

Maxila (Pr. 6, Fig. $6 \mathrm{~m}$ ") : com cinco lobos e sete espinhos ou curtas cerdas ao todo.

Maxilípede (Pr. 6, Fig. $6 \mathrm{mxp}$ ) : um artículo alongado com dois espinhos.

Patas 1 e 2 (Pr. 6, Figs. $6 \mathrm{pl}$ e $6 \mathrm{p} 2$ ) : representadas, cada uma, por um artículo bilobado: lobo externo com três espinhos e lobo interno com dois.

B - Anatomia dos estádios de copepódito

a) Caracteres gerais

Copepódito I (Prs. 9 e 10, Fig. 1)

Medindo-se 50 exemplares encontrou-se um comprimento médio igual a $388 \mu \mathrm{m}$.

Possui seis segmentos. As antênulas se estendem até quase a extremidade dos ramos da furca. As patas 1 e 2 são funcionais mas os ramos não são articulados. Há apenas um rudimento da terceira pata e parece haver primórdio da quarta. O abdome é composto por um único segmento. Cada ramo da furca apresenta duas cerdas curtas laterais - uma interna e outra externa - e três cerdas mais longas apicais sendo a do meio mais curta.

Copepódito II (Prs. 9 e 10, Fig. 2)

Mediram-se 50 exemplares: comprimento médio $=514 \mu \mathrm{m}$.

PRANCHA 10 - Copepóditos em vista dorsal

Fig. 1 - Copepódito I; Fig. 2 - Copepódito II; Fig. 3 - Copepódito III; Fig. 4 - Copepódito V $\sigma^{7}$; Fig. 5 - Copepódito IV; Fig. 6 - Copepódito V 9 . 


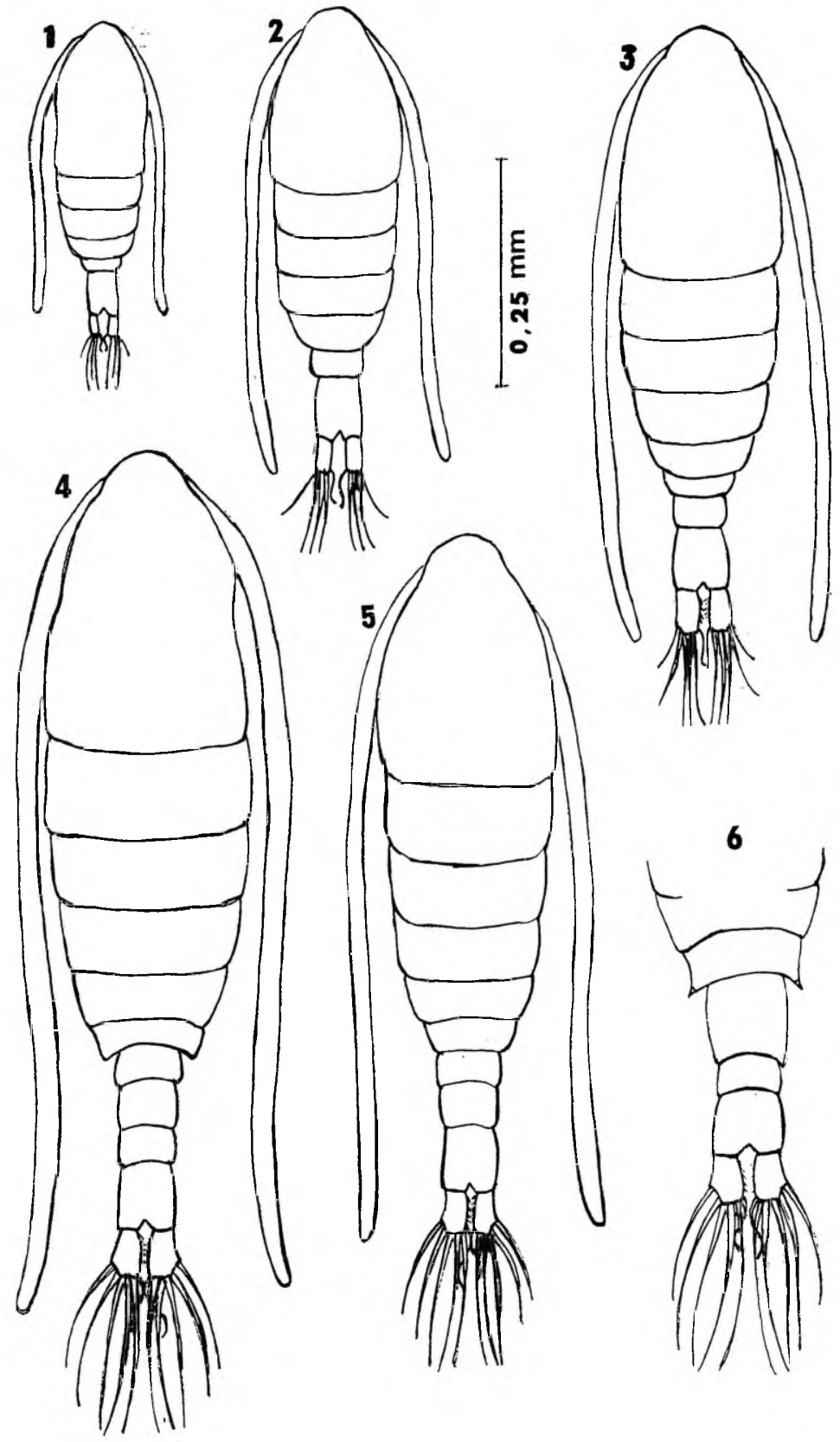


O corpo tem sete segmentos. As antênulas vão até a extremidade da furca. As patas 1 e 2 já possuem ramos articulados mas a 3 não. A quarta pata é rudimentar e há primórdios da quinta. $\mathrm{O}$ abdome é composto de um único segmento. Cada ramo da furca apresenta três cerdas apicais e duas menores laterais: uma interna e outra externa.

\section{Copepódito III (Prs. 9 e 10, Fig. 3)}

500 exemplares foram medidos: comprimento médio $=644 \mu \mathrm{m}$.

Possui oito segmentos, quatro pares de patas natatórias sendo os ramos do quarto par não articulados. O quinto par de patas é apenas rudimentar. O abdome é composto de dois segmentos sendo o primeiro quase a metade do segundo em comprimento. Cada ramo da furca apresenta 6 cerdas como no adulto e pequenas cérdulas na margem interna.

\section{Copepódito IV (Prs. 9 e 10, Fig. 5)}

Neste estádio já se pode notar diferenciação em macho e fêmea. 50 exemplares foram medidos: comprimento médio da fêmea $822 \mu \mathrm{m}$; comprimento médio do macho $768 \mu \mathrm{m}$.

Possuem nove segmentos. As antênulas da fêmea são iguais à esquerda do macho, mas a direita deste já apresenta diferenciação não visível a uma rápida observação mas sim ao microscópio. Aparecem quatro pares de patas natatórias com ramos articulados e que são iguais tanto no macho como na fêmea. A diferença principal entre ambos reside no quinto par de patas e pode ser observada facilmente à lupa: a direita do macho é maior que a esquerda e as da fêmea são iguais. O abdome é composto de três segmentos nos dois sexos. A fêmea se apresenta, desta fase em diante, como no adulto. 

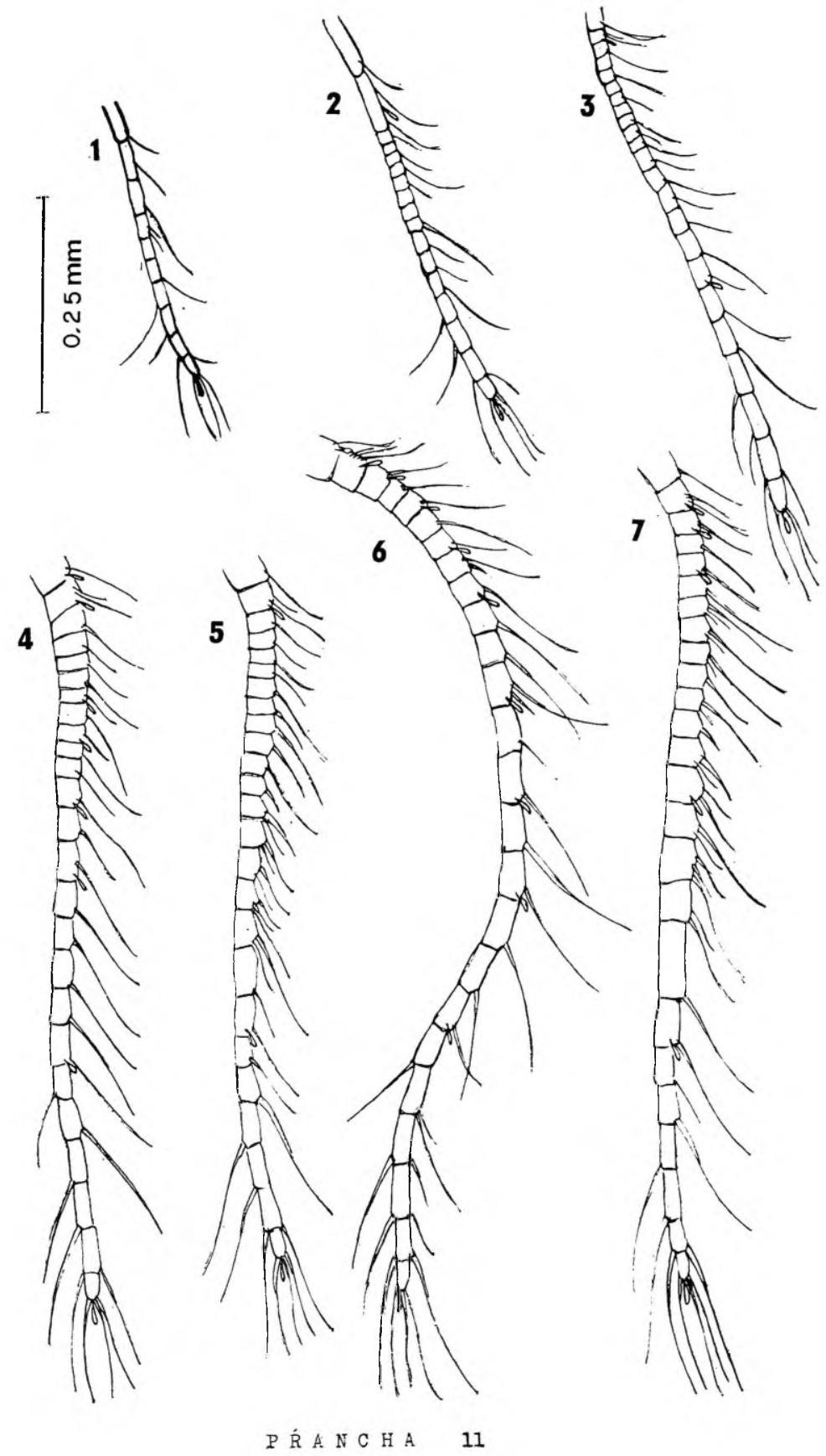
Copepódito V (Prs. 9 e 10, Figs. 4 e 6)

Mediram-se 50 exemplares de fêmea e 50 de macho. Comprimento médio da fêmea: $984 \mu \mathrm{m}$. Comprimento médio do macho: $894 \mu \mathrm{m}$.

A fêmea (Fig. 6) apresenta nove segmentos e o macho (Fig. 4) dez. Suas antênulas são iguais à esquerda do macho pois a direita deste já tem características da do adulto quanto à setação e desenvolvimento dos artículos.

Têm quatro pares de patas com ramos articulados e iguais no macho e na fêmea. O quinto par de patas é constituido por peças iguais na fêmea mas desiguais no macho, em que a direita é mais longa que a esquerda. $\mathrm{O}$ abdome da fêmea possui três segmentos (Fig. 6) sendo o primeiro, o dobro do segundo que se funde a este na forma adulta; abdome do macho com quatro segmentos. A furca se apresenta como na fase anterior.

b) Anatomia dos apêndices

\section{Copepódito I}

Antênula (Pr. 11, Fig. 1) : com 10 artículos ornamentados do proximal ao distal com o seguinte número de cerdas: $1: 1: 1: 2: 0$ : $1: 1: 1: 2: 3+1$ esteto.

Patas natatórias (Pr. 12)

Pata 1 (Fig. 1) : Fórmula das cerdas: exopódito: 2.3.1.; endopódito: 1.3.1.

Pata 2 (Fig. 2) : Fórmula das cerdas: exopódito: 1.3.1.; endopódito: 1.3 .1 .

\section{PRANCHA 12 - Patas natatórias dos copepóditos}

$$
\text { (Copepódito } \mathrm{I} \text { a } \mathrm{V}=\mathrm{CI}-\mathrm{CV} \text { ) }
$$

Fig. 1 - C I, pata 1; Fig. 2 - C I, pata 2; Fig. 3 - C II, pata 1; Fig. 4 - CII, pata 2; Fig. 5 - C II, pata 3; Fig. 6 - C III, pata 1; Fig. 7 - III, pata 2; Fig. 8 - C III, pata 3; Fig. 9 - C III, pata 4; Fig. $10-$ C IV, pata 1; Fig. 11 - C IV, pata 2; Fig. 12 - C IV, pata 3; Fig. 13 - C IV, pata 4; Fig. $14-$ C IV $\sigma^{\circ}$, quinto par de patas: $\mathrm{E}$ - pata esquerda, D - pata direita; Fig. 15 - CIV 9 , quinto par de patas; Fig. 16 - CV, pata 1; Fig. 17 - CV, pata 2; Fig. $18-\mathrm{CV}$, pata 3; Fig. $19-\mathrm{CV}$, pata 4; Fig. $20-\mathrm{CV} \sigma^{\circ}$, quinto par de patas: $\mathrm{E}-$ pata esquerda, D - pata direita; Fig. $21-\mathrm{CV}$. quinto par de patas. 

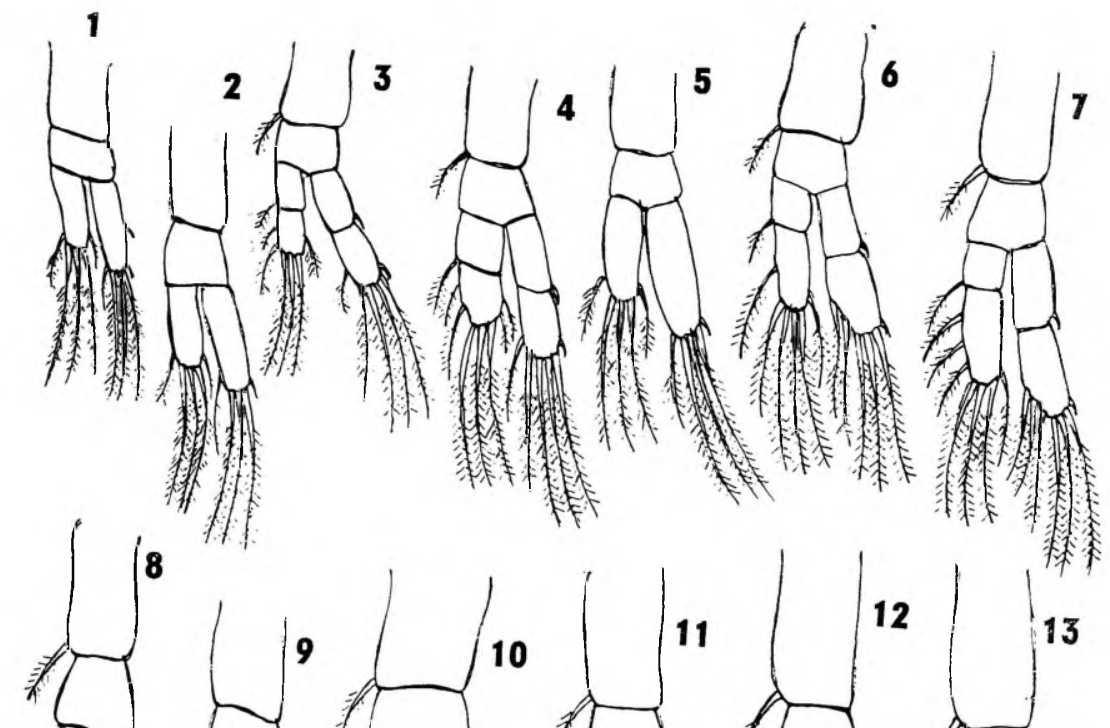

$19 / 10$
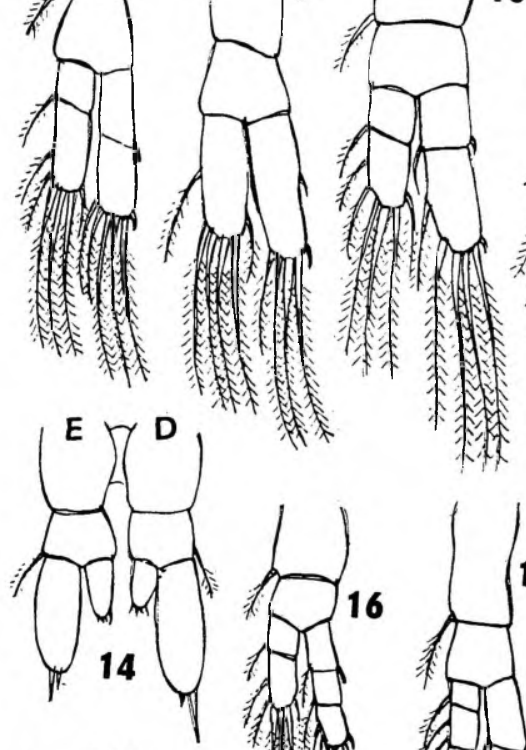

禁
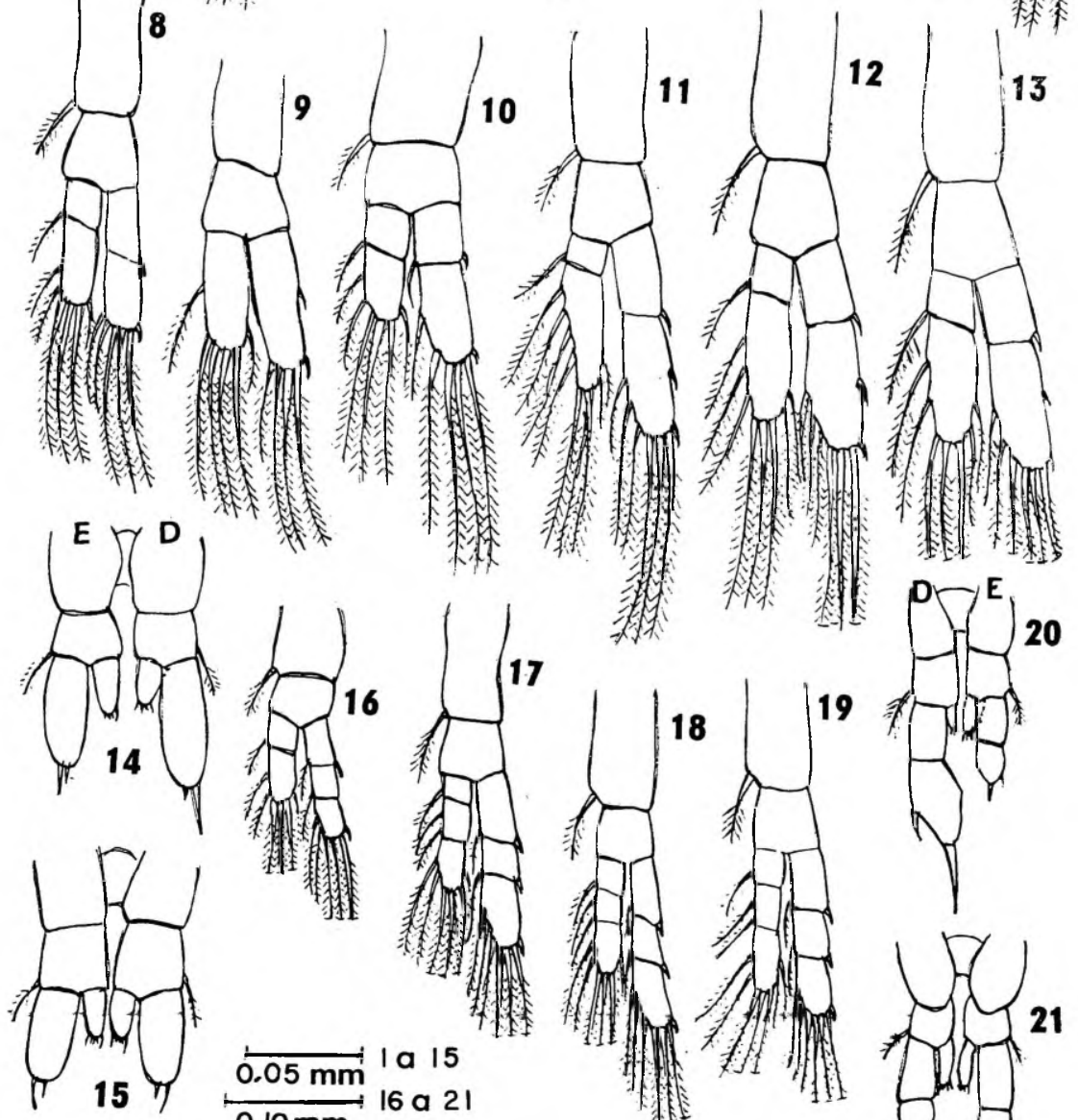

$\stackrel{0.05 \mathrm{~mm}}{1} \mathrm{a} 15$
$0,10 \mathrm{~mm}$
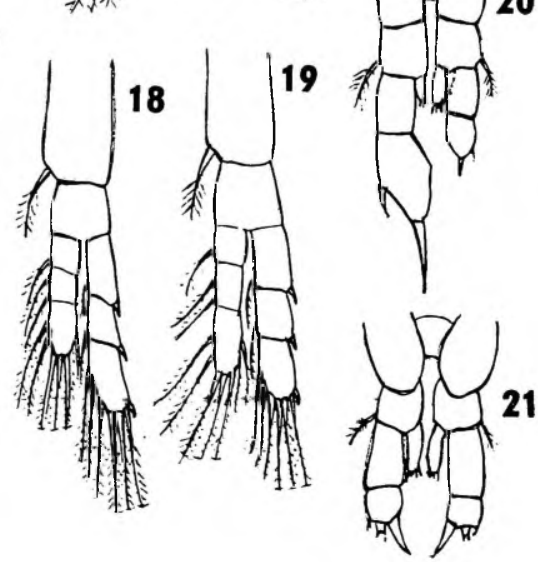


\section{Copepódito II}

Antênula (Pr. 11, Fig. 2) : com 17 artículos ornamentados do proximal ao distal com o seguinte número de cerdas: $1: 2+1$ esteto : 1 : $0: 1: 1: 1: 0: 0: 1: 1: 1: 1: 1: 1: 2: 3+1$ esteto.

Patas natatórias (Pr. 12)

Pata 1 (Fig. 3): coxa: 1 cerda interna; exopódito: 1: 1.3.2.; endopódito: 1: 1.3.2.

Pata 2 (Fig. 4): coxa: 1 cerda interna; exopódito: 1: 1.3.2.; endopódito: 1: 2.3.2.

Pata 3 (Fig. 5): exopódito: 1.3.1.; endopódito: 1.3.1.

\section{Copepódito III}

Antênula (Pr. 11, Fig. 3) : com 23 artículos ornamentados do proximal ao distal com o seguinte número de cerdas: $1: 2+1$ esteto: $1: 0: 1: 0: 1: 0: 1: 1: 1: 1: 1: 1: 1: 1: 1+1$ esteto: $1: 1$ : $1: 1: 2: 3+1$ esteto.

Patas natatórias (Pr. 12)

Pata 1 (Fig. 6) : coxa: 1 cerda interna; exopódito: 1 : 1.3.2.; endopódito: 1 : 1.3 .2 .

Pata 2 (Fig. 7) : coxa: 1 cerda interna; exopódito: 1 : 1.3.3.; endopódito: 1 : 1.3.3.

Pata 3 (Fig. 8) : coxa: 1 cerda interna; exopódito: 1 : 1.3.2.; endopódito: 1 : 1.3.2.

Pata 4 (Fig. 9) : exopódito: 2.3.1.; endopódito: 1.3.2.

\section{Copepódito IV}

Antênula da fêmea = esquerda do macho (Pr. 11, Fig. 4): com 25 artículos. Cerdas dos artículos do proximal ao distal: $1+1$ esteto: $2+1$ esteto: $1: 1: 1: 1: 1+1$ esteto: $1: 1+1$ esteto: $1: 1: 1+1$ esteto: $1: 1+1$ esteto: $1: 1: 1: 1: 1+1$ esteto: $1: 1: 1: 1: 2$ : $3+1$ esteto.

Antênula direita do macho (Pr. 11, Fig. 5): com 25 artículos. Cerdas dos artículos do proximal ao distal: $1: 2+1$ esteto: $1: 1: 1$ : $1: 1: 1: 1: 1: 1: 1$ espinho: $1+1$ espinho : $2: 2: 3: 2: 1$ : $1+1$ esteto: $1: 1: 1: 1: 2: 3+1$ esteto. 


\section{Patas natatórias (Pr. 12)}

Pata 1 (Fig. 10) : coxa: 1 cerda interna; exopódito: 1.1 : 1.3.2; endopódito: $1: 1.3 .2$.

Pata 2 (Fig. 11) : coxa: 1 cerda interna; exopódito: 1 : 2.3.3; endopódito: $1: 2.3 .4$.

Pata 3 (Fig. 12) : coxa: 1 cerda interna; exopódito: 1 : 2.3.3; endopódito: 1 : 2.3 .3$.

Pata 4 (Fig. 13) : coxa: 1 cerda interna; exopódito: 1 : 2.3.3.; endopódito: 1 : 2.3 .2 .

Quintos pares de patas (Figs. 14 e 15)

5..$^{\circ}$ par de patas da fêmea (Fig. 15) : com coxa, base, endopódito e exopódito. Base: com pequena cerda externa próximo ao exopódito. Endopódito: não articulado e com dois espinhos apicais e uma série de cerdas curtas entre eles. Exopódito: não articulado e com dois espinhos apicais sendo o externo maior que o interno.

$5 .^{\circ}$ par de patas do macho (Fig. 14) : com coxa, base, endopódito e exopódito. Base: com uma cerda externa próximo ao exopódito. Endopódito: não articulado sendo o da direita (Fig. $14 \mathrm{D}$ ) pouco menor que o da esquerda (Fig. $14 \mathrm{E}$ ) e apresentando em seu ápice dois espinhos e uma série de pequenas cerdas ao passo que o esquerdo possui um só espinho e uma série de cerdas curtas. Exopódito: não articulado sendo o da direita (Fig. 14 D) pouco maior que o da esquerda (Fig. $14 \mathrm{E}$ ). Ambos apresentam dois espinhos apicais: o externo maior que o interno. Entre os externos, o da direita é maior que o da esquerda.

\section{Copepódito V}

Antênulas da fêmea (Pr. 11, Fig. 6) = antênula esquerda do màcho: com 25 artículos. Cerdas do artículo proximal ao distal: $1+1$ esteto : $3+1$ esteto : $1+1$ esteto : $1: 1+1$ esteto: $1: 1+1$ esteto : $1+1$ espinho : $1+1$ esteto $: 1: 1: 1+1$ espinho +1 esteto: $1: 1+1$ esteto : $1: 1+1$ esteto $: 1: 1: 1+1$ esteto $: 1: 2: 2: 2: 2:$ : $3+1$ esteto.

Aintênula direita do macho (Pr. 11, Fig. 7): com 25 artículos. Cerdas do artículo proximal ao distal: $1: 2+1$ esteto : $1+1$ esteto : 
$1: 1+1$ esteto : $1: 3: 2: 2: 1: 2: 1$ espinho : $1+1$ espinho : $1+1$ espinho +1 esteto : $2: 3: 2: 1: 1+1$ esteto $: 1: 1: 1: 1: 2$ : $3+1$ esteto.

Patas natatórias (Pr. 12)

Pata 1 (Fig. 16): coxa: 1 cerda interna; exopódito: 1.1 : 1 : 1.3.2; endopódito: $1: 1.3 .2$.

Pata 2 (Fig. 17): coxa: 1 cerda interna; exopódito: 1.1 : 1.1 : 2.3.3; endopódito: 1 : 2 : 2.3.2.

Pata 3 (Fig. 18) : coxa: 1 cerda interna; exopódito: 1.1 : 1.1 : 1.3.3; endopódito: $1: 2: 2.3 .2$.

Pata 4 (Fig. 19) : cox $\alpha$ : 1 cerda interna; exopódito: 1.1 : 1.1 : 1.3.3; endopódito: $1: 2$ : 2.3.2.

Quintos pares de patas (Figs. 20 e 21)

5. par de patas da fêmea (Fig. 21): Base: com pequena cerda lateral externa. Endopódito: não articulado, com dois fortes espínulos e uma série de cerdas curtas na extremidade. Exopódito: com dois artículos: $2 .^{\circ}$ artículo com um espinho curto do lado externo apical; dois espinhos pouco maiores fundidos na base e que corresponderão ao terceiro artículo no adulto. Ainda na extremidade, um grande espinho recurvado para a região interna.

5. ${ }^{\circ}$ par de patas do macho (Fig. 20) : Base: Com uma cerda lateral externa próximo ao exopódito. Endopódito esquerdo (Fig. 20 E) : quase do mesmo comprimento que o primeiro artículo do exopódito. Apresenta um espinho apical e uma série de cerdas curtas. Endopódito direito (Fig. 20 D) : bem menor que o esquerdo e menor que a metade do comprimento do primeiro artículo do exopódito direito. Possui dois espínulos e uma série de cerdas curtas na extremidade. Exopódito esquerdo (Fig. $20 \mathrm{E}$ ) : com dois artículos tendo o segundo um espinho apical e outro lateral externo. Não alcança a região média do segundo artículo do exopódito direito. Exopódito direito (Fig. $20 \mathrm{D}$ ) : com dois artículos sendo o segundo quase o dobro do primeiro em comprimento. Apresenta um longo espinho apical, quase do comprimento do artículo em que se insere, e um lateral externo menor. 


\section{DISCUSSÃO}

Como já se teve oportunidade de dizer, poucas foram as espécies de Diaptomus cujas fases naupliares e de copepódito foram estudadas sob o ponto de vista morfológico. Entre elas encontram-se $D$. castor, cujas fases foram descritas por Gurney (1931), D. vulgaris cujas fases naupliares e primeira fase de copepódito foram descritas por Dietrich (1915), D. clavipes do qual só foram descritas as fases de copepódito por Kamal e Armitage (1967). Os aspectos das fases naupliares dessas espécies e de $D$. corderoi são comparados abaixo:

\section{NĀUPLIO I}

D. corderoi

$145 \mu \mathrm{m}$

Comprimento médio do corpo

Segmentação

N. ${ }^{\circ}$ de cerdas dos apêndices e outras estruturas

Inexistente

Antênula:

$1 .^{\circ}$ art. 0

$2 .^{\circ}$ art. 3
D. vulgaris

$175 \mu \mathrm{m}$

$3 .^{\circ}$ art. 3

Antena:

coxa

base

endopódito 3

exopódito 6

Mandíbula:

coxa

base

endopódito 6

exopódito 5

Furca

sem lobos

duas cerdas
Inexistente

Inexistente Inexistente

$\begin{array}{lll} & 0 & 0 \\ & 3 & 3 \\ & 3 & 3 \\ 1 & & \\ 2 & 2 & 1 \\ 3 & 2 & 3 \\ 6 & 4 & 4 \\ 1 & 6 & 6 \\ 2 & 1 & \\ 6 & 2 & 2 \\ 5 & 6 & 6 \\ & 5 & 5\end{array}$

sem lobos duas cerdas sem lobos duas cerdas 


\section{NÁUPLIO II}
D. corderoi
D. vulgaris
D. castor

Comprimento médio do corpo

$$
165 \mu \mathrm{m}
$$

N. ${ }^{\circ}$ de cerdas dos apêndices e outras estruturas
Antênula:

$10^{\circ}$ art. 0

$2 .^{\circ}$ art. 3

0
3

$3 .^{\circ}$ art. $3+1$

$4+1$ fileira de cér-

esteto +2 fileiras dulas

de cérdulas

Antena:

$\begin{array}{ll}\text { coxa } & 3 \\ \text { base } & 3 \\ \text { endopódito } & 5 \\ \text { exopódito } & 7\end{array}$

3

3

4

1

3

5

7

Mandíbula:

$\begin{array}{ll}\text { coxa } & 1 \\ \text { base } & 3 \\ \text { exopódito } & 6 \\ \text { endopódito } & 9\end{array}$

1
2
6
7

1

2

8

Maxílula:

1 fileira de cér- 1 fileira de cér- 1 fileira de cérdulas dulas dulas

Maxila:

1 fileira de cér- 1 fileira de cér- 1 fileira de cérdulas dulas dulas

Maxilipede:

1 fileira de cér- 1 fileira de cér- 1 fileira de cérdulas dulas dulas

Furca

2 lobos

2 lobos

2 lobos

2 cerdas de igual 2 cerdas, de tama- 2 cerdas de mesmo tamanho: a da di- nhos diferentes: di- tamanho: a da direita inclinada para reita maiof que es- reita inclinada para o dorso querda 
NÁUPLIO III

\section{D. corderoi}

$184 \mu \mathrm{m}$

Comprimento médio do corpo

Segmentação
D. vulgaris

$230 \mu \mathrm{m}$

1 início
0

3

6

$\begin{array}{ll}3 & ? \\ 4 & ? \\ 6 & ? \\ 8 & ?\end{array}$

Mandíbula:

$\begin{array}{ll}\text { coxa } & 1 \\ \text { base } & 3 \\ \text { endopódito } & 10 \\ \text { exopódito } & 6\end{array}$

Maxílula:

saliência espinhos

com 2

Maxila:

pequeno espinho

Maxilípede:

1 fileira de cérdulas
D. castor

$295 \mu \mathrm{m}$
N. ${ }^{\circ}$ de cerdas dos
apêndices e outras estruturas
Furca
2 lobos maiores

4 cerdas de igual tamanho; duas em cada lobo; dorsal direita mais inclinada para o dorso que a esquerda
2 lobos

cerdas: 2 ventrais 4 cerdas de igual de tamanhos dife- tamanho; dorsais rentes: direita maior bifurcadas na extreque esquerda; dor- midade e a direita sais de mesmo ta- mais inclinada para manho e bifurcadas o dorso que a esna extremidade querda

? = descrição incompleta 
D. corderoi

Comprimento médio do corpo

\section{Segmentação}

N. ${ }^{\circ}$ de cerdas dos apêndices e outras estruturas

$$
254 \mu \mathrm{m}
$$

1 início

Antênula :

$1 .^{\circ}$ art

$2 .^{\circ}$ art.
$3 .^{\circ}$ art. $9+1$ esteto

Antena:

$\begin{array}{lr}\text { coxa } & 3 \\ \text { base } & 4 \\ \text { endopódito } & 7 \\ \text { exopódito } & 10\end{array}$

Mandíbula:

coxa: 1 + lâmina c/4 dentes

base 5

endopódito 10 exopódito

6

Maxilula:

1 artículo: 7

Maxila:

1 espinho maior

Maxilípede:

1 fileira de cérdulas

Furca
2 lobos maiores
2 lobos
4 cerdas de igual 4 cerdas: duas ven- tamanho; duas em trais de tamanhos cada lobo; dorsal diferentes; direita direita mais inclina- maior que esquerda; da para o dorso que a esquerda

D. vulgaris

$280 \mu \mathrm{m}$

1 início

0

11

3

4

8

1 + lâmina

4
13

6

2 arts: 7

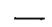

$?$

?

placa bilobada com cerdas curtas

2 lobos

4 cerdas de mesmo tamanho; dorsais bifurcadas e a direita mais inclinada para o dorso que a esquerda 


\section{NÃUPLIO V}

\section{D. corderoi}

Comprimento médio do corpo

Segmentação

N. ${ }^{\circ}$ de cerdas dos apêndices e outras estruturas

$$
291 \mu \mathrm{m}
$$

3 inícios

Antênula:

$20^{\circ}$ art. 3
$1 .^{\circ}$ art.

3. ${ }^{\circ}$ art. $13+1$ esteto

Antena:

coxa

base

$\begin{array}{lr}\text { endopódito } & 8 \\ \text { exopódito } & 11\end{array}$

Mandíbula:

$$
\text { coxa: } 1 \text { + lâmina }
$$$$
\text { c/5 dentes }
$$

base 5

endopódito 11

exopódito
D. vulgaris

$322 \mu \mathrm{m}$

1 início
D. castor

?

$?$

0

3

$13+1$ esteto
2

9

8

9

1 + lâmina

5
10
6

1 + lâmina

4

9

6

0

11

Maxílula:

1. ${ }^{\circ}$ art.

0

2

5

11

$2 .^{\circ}$ art.

12

14

Maxila:

1 art.: 2 espinhos 1 art.: 2 espinhos +1 art.: 2 espinhos cérdulas

$$
\begin{aligned}
& \text { Maxi- } \\
& \text { lipede: } \\
& \text { P1 } \\
& \text { P2 }
\end{aligned}\left\{\begin{array}{l}
1 \text { fileira } \\
\text { de cér- } \\
\text { dulas ca- } \\
\text { da um }
\end{array}\right.
$$

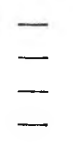

2 lobos

2 lobos

4 cerdas de igual tamanho: dorsal direita mais inclinada para o dorso que a esquerda
4 cerdas: duas ven- 4 cerdas de mesmo trais de tamanhos tamanho: dorsais diferentes: direita bifurcadas e a dimaior que esquerda; reita mais inclinada dorsais de igual ta- para o dorso que a manho e bifurcadas esquerda 
D. corderoi

Comprimento mé-
dio do corpo

Segmentação

N. de cerdas dos apêndices e outras estruturas

$$
345 \mu \mathrm{m}
$$

3 inícios

Antênula:

$1.0^{\circ}$ art

$20^{\circ}$ art. 3
$3 .^{\circ}$ art. $16+1$ esteto

Antena:

coxa

base

endopódito 9

exópodito 12

Mandíbula:

coxa: 1 + lâmina c/5 dentes

base 5

endopódito 11 exopódito
D. vulgaris

$370 \mu \mathrm{m}$

3 inícios
D. castor

$500 \mu \mathrm{m}$

3 inícios

1
2
16 esteto

2
5
9
12

1 + lâmina

5

$\stackrel{?}{6}$

3

13

1 art.: 11 espinhos

1 art.: 2 espinhos

6 cerdas: as duas recém surgidas são internas, mais curtas que as externas e levemente recurvadas para o dorso
1 + lâmina com 8 cérdulas

5

11

6

1
16

$?$

1 art.: 2 espinhos
2 lobos

6 cerdas: as duas recém surgidas ventrais internas são menores que as ventrais externas e também de tamanhos diferentes: a direita menor que a esquerda
3

4

3

3

2

$\begin{array}{ll}\text { lobo externo } & 3 \\ \text { lobo interno } & 2\end{array}$

2 lobos

3

3

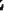

3

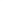

Furca 
Quanto às fases de copepódito, comparando-se $D$. corderoi com $D$. castor, observa-se que em $D$. corderoi só aparecem seis cerdas furcais a partir do estádio III ao passo que em $D$. castor a partir do segundo estádio. Há também diferenças na setação das antênulas e no quinto par de patas do copepódito macho no estádio $\mathrm{V}$; o endopódito em $D$. castor possui dois artículos, mas não é articulado em $D$. corderoi; o segundo artículo dos exopóditos tem três espinhos em $D$. castor e apenas dois em $D$. corderoi. Estes caracteres que distinguem o quinto copepódito macho de $D$. castor do de $D$. corderoi são em $D$. clavipes iguais aos de $D$. corderoi, isto é, apresenta endopódito não articulado e apenas dois espinhos no segundo artículo do exopódito. No entanto há diferenças quanto ao aspecto geral dessas peças que podem ser usadas para distingui-los assim como as fêmeas.

De um modo geral, a anatomia grosseira dos copepóditos de $D$. clavipes é igual à de $D$. corderoi. As diferenças que apresentam entre si situam-se principalmente na setação das antênulas e no tamanho do corpo cuja comparação pode ser feita pelas Tabelas 1 e 2 .

Quanto ao comprimento das formas larvais de $D$. corderoi, verifica-se que há superposição de intervalos de comprimento (campos de variação) das fases de náuplios I e II, II e III, IV e V, V e VI, VI e copepóditos I, V macho e VI macho (adulto), assim como há superposição dos intervalos de variação de copepóditos IV macho e IV fêmea, $V$ macho e $V$ fêmea, adulto macho e adulto fêmea.

\section{CONCLUSÕES}

Diaptomus corderoi apresenta seis fases naupliares e seis de copepódito, a última destas constituindo a forma adulta, assim como acontece em outras espécies de Diaptomus.

Entre as fases naupliares, as principais alterações foram o alongamento do corpo, modificação da posição e número das cerdas furcais, aumento do número de estruturas no terceiro artículo das antênulas, aparecimento dos esboços dos apêndices posteriores às mandíbulas e da lâmina mandibular.

O primeiro estádio naupliar distingue-se bem do náuplio II por sua forma bem ovalada e por apresentar as cerdas furcais bem pe- 
TABELA 1

Armadura das antênulas dos copepóditos I a V de $D$. corderoi.

Convenções: $\mathrm{a}=$ esteto; $\mathrm{sp}=$ espinho; os algarismos se referem ao número de cerdas; $E=$ esquerda; $D=$ direita

\begin{tabular}{|c|c|c|c|c|c|c|c|}
\hline Fase & I & II & III & $\begin{array}{l}\text { IV우 e } \\
\text { IV E } \sigma^{\circ}\end{array}$ & IV Do & $\begin{array}{l}\mathrm{V} q \text { e } \\
\text { VE } \text { E }^{\circ}\end{array}$ & $\mathrm{V} \mathrm{Do}$ \\
\hline $\begin{array}{l}\text { N.० de } \\
\text { artículos }\end{array}$ & $\begin{array}{l}10 \\
1 \\
1 \\
1 \\
2 \\
0 \\
1 \\
1 \\
1 \\
2 \\
3+1\end{array}$ & $\begin{array}{l}17 \\
1 \\
2+a \\
1 \\
0 \\
1 \\
1 \\
1 \\
0 \\
0 \\
1 \\
1 \\
1 \\
1 \\
1 \\
2 \\
3+1\end{array}$ & $\begin{array}{l}23 \\
1 \\
2+\mathrm{a} \\
1 \\
0 \\
1 \\
0 \\
1 \\
0 \\
1 \\
1 \\
1 \\
1 \\
1 \\
1 \\
1 \\
1+\mathrm{a} \\
1 \\
1 \\
1 \\
1 \\
2 \\
3+\mathrm{a}\end{array}$ & $\begin{array}{l}25 \\
1+\mathrm{a} \\
2+\mathrm{a} \\
1 \\
1 \\
1 \\
1 \\
1+\mathrm{a} \\
1 \\
1+\mathrm{a} \\
1 \\
1 \\
1+\mathrm{a} \\
1+\mathrm{a} \\
1 \\
1 \\
1 \\
1 \\
1+\mathrm{a} \\
1 \\
1 \\
1 \\
1 \\
2 \\
3+\mathrm{a}\end{array}$ & $\begin{array}{l}25 \\
1 \\
2+\mathrm{a} \\
1 \\
1 \\
1 \\
1 \\
1 \\
1 \\
1 \\
1 \\
1 \\
\mathrm{sp} \\
2 \\
2 \\
3 \\
2 \\
1 \\
1+\mathrm{a} \\
1 \\
1 \\
1 \\
1 \\
2 \\
3+\mathrm{a}\end{array}$ & $\begin{array}{l}25 \\
1+\mathrm{a} \\
3+\mathrm{a} \\
1+\mathrm{a} \\
1 \\
1+\mathrm{a} \\
1 \\
1+\mathrm{a} \\
1+\mathrm{sp} \\
1+\mathrm{a} \\
1 \\
1 \\
1+\mathrm{sp}+\mathrm{a} \\
1+\mathrm{a} \\
1 \\
1+\mathrm{a} \\
1 \\
1 \\
1+\mathrm{a} \\
1 \\
2 \\
2 \\
2 \\
2 \\
3+\mathrm{a}\end{array}$ & $\begin{array}{l}25 \\
1 \\
2+\mathrm{a} \\
1+\mathrm{a} \\
1 \\
1+\mathrm{a} \\
1 \\
3 \\
2 \\
2 \\
1 \\
2 \\
\mathrm{sp} \\
1+\mathrm{sp}+\mathrm{a} \\
2 \\
3 \\
2 \\
1 \\
1+\mathrm{a} \\
1 \\
1 \\
1 \\
1 \\
2 \\
3+\mathrm{a}\end{array}$ \\
\hline
\end{tabular}

quenas e paralelas o que não acontece com o segundo náuplio cuja forma do corpo é menos ovalada (mais alongada) e uma das cerdas furcais, a da direita, é voltada para o dorso.

Para diferenciar o náuplio III do náuplio II, pode-se usar a presença de duas cerdas em cada lobo da furca do náuplio III.

Entre náuplio III e náuplio IV a distinção é fácil observando-se o quarto par de apêndices que na quarta fase é bem mais desenvolvido que na terceira.

Quando o náuplio passa do quarto estádio para o quinto, há o aparecimento de duas séries de cérdulas correspondentes às patas 1 e 2; a maxílula, que apresentava um artículo na fase IV passa a ter 
TABELA 2

Armadura das antênulas dos copepóditos de $D$. clavipes

Convenções: $\mathrm{a}=$ esteto; $\mathrm{sp}=$ espinho; os algarismos se referem ao número de cerdas; $\mathrm{E}=$ esquerda; $\mathrm{D}=$ direita

\begin{tabular}{|c|c|c|c|c|c|c|c|}
\hline Fase & I & II & III D & III E & IV D & $\mathrm{VE}$ & V D \\
\hline $\begin{array}{l}\mathrm{N} \cdot{ }^{\circ} \text { de } \\
\text { artículos }\end{array}$ & $\begin{array}{l}10 \\
1 \\
1 \\
1 \\
1 \\
0 \\
1 \\
1 \\
2 \\
2 \\
5+a\end{array}$ & $\begin{array}{l}12 \\
1 \\
1+\mathrm{a} \\
2 \\
0 \\
1 \\
0 \\
1 \\
0 \\
0 \\
0 \\
1 \\
1 \\
1 \\
1 \\
2 \\
2 \\
2 \\
5+\mathrm{a}\end{array}$ & $\begin{array}{l}23 \\
1 \\
2+\mathrm{a} \\
1+\mathrm{a} \\
0 \\
1 \\
0 \\
1 \\
0 \\
1 \\
\mathrm{sp} \\
1 \\
1+\mathrm{a} \\
1 \\
1 \\
1 \\
1 \\
1+\mathrm{a} \\
1 \\
1 \\
2 \\
2 \\
2 \\
5+\mathrm{a}\end{array}$ & $\begin{array}{l}23 \\
1 \\
2+\mathrm{a} \\
1+\mathrm{a} \\
0 \\
1 \\
0 \\
1 \\
0 \\
1 \\
\mathrm{sp} \\
1 \\
1+\mathrm{a} \\
1 \\
1 \\
1 \\
1 \\
1 \\
1 \\
1 \\
2 \\
2 \\
2 \\
5+\mathrm{a}\end{array}$ & $\begin{array}{l}25 \\
1+\mathrm{a} \\
3+\mathrm{a} \\
1+\mathrm{a} \\
1 \\
1+\mathrm{a} \\
1 \\
1 \\
\mathrm{sp} \\
1 \\
1 \\
1 \\
1+\mathrm{sp}+\mathrm{a} \\
1 \\
1+\mathrm{a} \\
1 \\
1+\mathrm{a} \\
1 \\
1 \\
1 \\
1 \\
1 \\
2 \\
2 \\
2 \\
5+\mathrm{a}\end{array}$ & $\begin{array}{l}25 \\
1+\mathrm{a} \\
3+\mathrm{a} \\
1+\mathrm{a} \\
1 \\
1+\mathrm{a} \\
1 \\
1+\mathrm{a} \\
1+\mathrm{sp} \\
2+\mathrm{a} \\
1 \\
2 \\
1+\mathrm{sp}+\mathrm{a} \\
1 \\
1+\mathrm{a} \\
1 \\
1+\mathrm{a} \\
1 \\
1 \\
1+\mathrm{a} \\
1 \\
1 \\
2 \\
2 \\
2 \\
5+\mathrm{a}\end{array}$ & $\begin{array}{l}25 \\
1+\mathrm{a} \\
3+\mathrm{a} \\
1+\mathrm{a} \\
1 \\
1+\mathrm{a} \\
1 \\
1+\mathrm{a} \\
2 \mathrm{sp} \\
2+\mathrm{a} \\
2 \\
2 \\
1+\mathrm{sp}+\mathrm{a} \\
1+\mathrm{sp}+\mathrm{a} \\
2+\mathrm{a} \\
2+\mathrm{a} \\
2+\mathrm{a} \\
1+\mathrm{sp}+\mathrm{a} \\
1+\mathrm{sp}+\mathrm{a} \\
2 \mathrm{sp} \\
\mathrm{sp} \\
1 \\
2 \\
2 \\
2 \\
5+\mathrm{a}\end{array}$ \\
\hline
\end{tabular}

dois na fase $\mathrm{V}$ e a maxila, de um espinho passa a um artículo com dois espinhos. Pela primeira antena também podem ser distinguidos: o estádio IV com 9 cerdas e 1 esteto no terceiro artículo e o V com 13 cerdas e 1 esteto.

A primeira antena pode ser utilizada desde o terceiro estádio para a identificação das fases pois o número de estruturas do terceiro artículo varia de fase para fase. No entanto sua observação não é muito fácil.

O $6 .^{\circ}$ estádio naupliar é logo diferenciado do $5 .^{\circ}$ por apresentar 6 cerdas furcais e maior desenvolvimento dos apêndices $4 .^{\circ}$ a $8 .^{\circ}$. 
As outras modificações observadas durante o crescimento como, alteração na setação dos apêndices, aparecimento da lâmina mastigadora da mandíbula a partir do quarto estádio, não são muito úteis na identificação das fases naupliares quando se observa o animal vivo.

A distinção dos copepóditos pode ser feita facilmente pelo número de patas natatórias nos estádios I, II, III e IV, e pela relação entre os tamanhos da quinta pata direita e esquerda nos estádios IV e $\mathrm{V}$ do macho pois no estádio IV a quinta pata direita é levemente maior que a esquerda e no $\mathrm{V}$ é bem maior.

Pelo número de segmentos do abdome também podem ser distinguidos os copepóditos I e II de III, III de IV e IV de V Os copepóditos I e II apresentam um segmento abdominal, III tem dois, IV possui três, o $\mathrm{V}_{0}^{*}$ e $\mathrm{V}$ q possuem respectivamente 4 e 3 segmentos, sendo que o primeiro abdominal da fêmea é bem maior que o segundo, podendo ser usado para distinguir a quarta fase da quinta fase feminina.

As antênulas são bastante diferentes nas várias fases em virtude da alteração no número de artículos, cerdas, espinhos e estetos.

Estudando-se a morfologia das patas natatórias, nota-se que hả diferenciação de um estádio para outro, às vezes quanto às cerdas, outras, quanto ao número de artículos.

A distinção entre macho e fêmea nos estádios IV e $V$ pode ser feita pelo quinto par de patas que apresenta diferenças quanto ao número de cerdas, espinhos e tamanho do exopódito de uma pata em relação à outra na mesma fase. Os machos, por terem a quinta pata direita pouco maior que a esquerda são facilmente distinguidos da fêmea que as possui iguais.

Verifica-se que o aspecto geral, que não pode ser traduzido com palavras, é o que proporciona, à primeira vista a diferenciação da fase naupliar de uma espécie da mesma fase de outra espécie. No entanto existem dois caracteres, o último artículo da antênula e a furca que podem ser comparados quando várias espécies são estudadas, como se vê abaixo.

N. ${ }^{\circ}$ de cerdas do terceiro artículo da antênula no náuptio: 


\begin{tabular}{|c|c|c|c|c|c|c|}
\hline \multirow[t]{2}{*}{ Espécies } & \multicolumn{6}{|c|}{ Fases naupliares } \\
\hline & I & II & III & IV & $\mathrm{V}$ & VI \\
\hline D. corderoi & 3 & $\begin{array}{l}3+a+2 \text { séries } \\
\text { de cérdulas }\end{array}$ & $6+a$ & $9+a$ & $13+a$ & $16+a$ \\
\hline D. vulgaris & 3 & $\begin{array}{l}4+1 \text { série de } \\
\text { cérdulas }\end{array}$ & 6 & 11 & 14 & 16 \\
\hline D. castor & 3 & $3+a$ & 6 & $9+a$ & $13+a$ & $16+a$ \\
\hline
\end{tabular}

Como se verifica, o caráter "antênula" não pode ser usado sempre para distinguir as espécies pois, apresenta o mesmo aspecto em determinadas fases de espécies diferentes. Sendo assim, utiliza-se o caráter "furca" para distinguí-las a partir do segundo estádio.

No entanto, esses dois caracteres não podem ser usados para os náuplios I, os quais são diferenciados apenas pela antena cuja setação da coxa, base, endopódito e exopódito é a seguinte:

D. corderoi: $1 ; 2 ; 3 ; 6$

D. vulgaris: $2 ; 2 ; 4 ; 6$

D. castor: $1 ; 3 ; 4 ; 6$

Para os copepóditos conclui-se que o caráter que mais varia com a mudança de fase é a articulação e setação das antênulas e, a partir do quarto copepódito, o quinto par de patas, podendo então ser usado para distinguir um mesmo estádio de espécies distintas.

Com relação ao crescimento de $D$. corderoi, observando-se os campos de variação dos comprimentos, conclui-se que não devem ser usados para identificar os náuplios pois superpõem-se às vezes.

\section{RESUMO}

Diaptomus corderoi apresenta 6 fases naupliares e 6 de copepódito, sendo a $6{ }^{\mathrm{a}}$ a forma adulta, cujas características são apresentadas nos quadros 1 e 2 . 
Não existe só um caráter para distinguir as fases naupliares de $D$. corderoi das de $D$. vulgaris e $D$. castor como se vê logo a seguir onde cada estádio naupliar é diferenciado nas várias espécies.

Náuplio I: Antena

D. corderoi - coxa: 1; base: 2; endopódito: 3, exopódito: 6

D. vulgaris - coxa: 2; base: 2; endopódito: 4; exopódito: 6

D. castor - coxa: 1; base: 3; endopódito: 4; exopódito: 6

Náuplio II: $3 .^{\circ}$ artículo da antênula

D. corderoi -3 cerdas +1 esteto +2 fileiras de cérdulas

D. vulgaris -4 cerdas +1 fileira de cérdulas

D. castor -3 cerdas +1 esteto.

Náuplio III, IV, V e VI: Furca com os seguintes caracteres:

D. corderoi - cerdas ventrais de tamanhos iguais e dorsais não bifurcadas.

D. vulgaris - cerdas ventrais de tamanhos diferentes e dorsais bifurcadas.

D. castor - cerdas ventrais de tamanhos iguais e dorsais bifurcadas.

A distinção de uma fase de copepódito de uma espécie, da mesma fase de outra espécie pode ser feita pelas antênulas cujo número de artículos e armadura devem ser observados. Da fase IV em diante a diferenciação é feita mais facilmente pelas quintas patas tanto de machos como de fêmeas.

A G R A D E C I M N T O S

- à Fundação de Amparo à Pesquisa do Estado de São Paulo que tornou possivel este trabalho.

- ao Departamento de Zoologia, do Instituto de Biociências, pelo empréstimo de material e local de trabalho.

- e, à Prof. Dra. Tagea K. S. Björnberg pela orientação. 


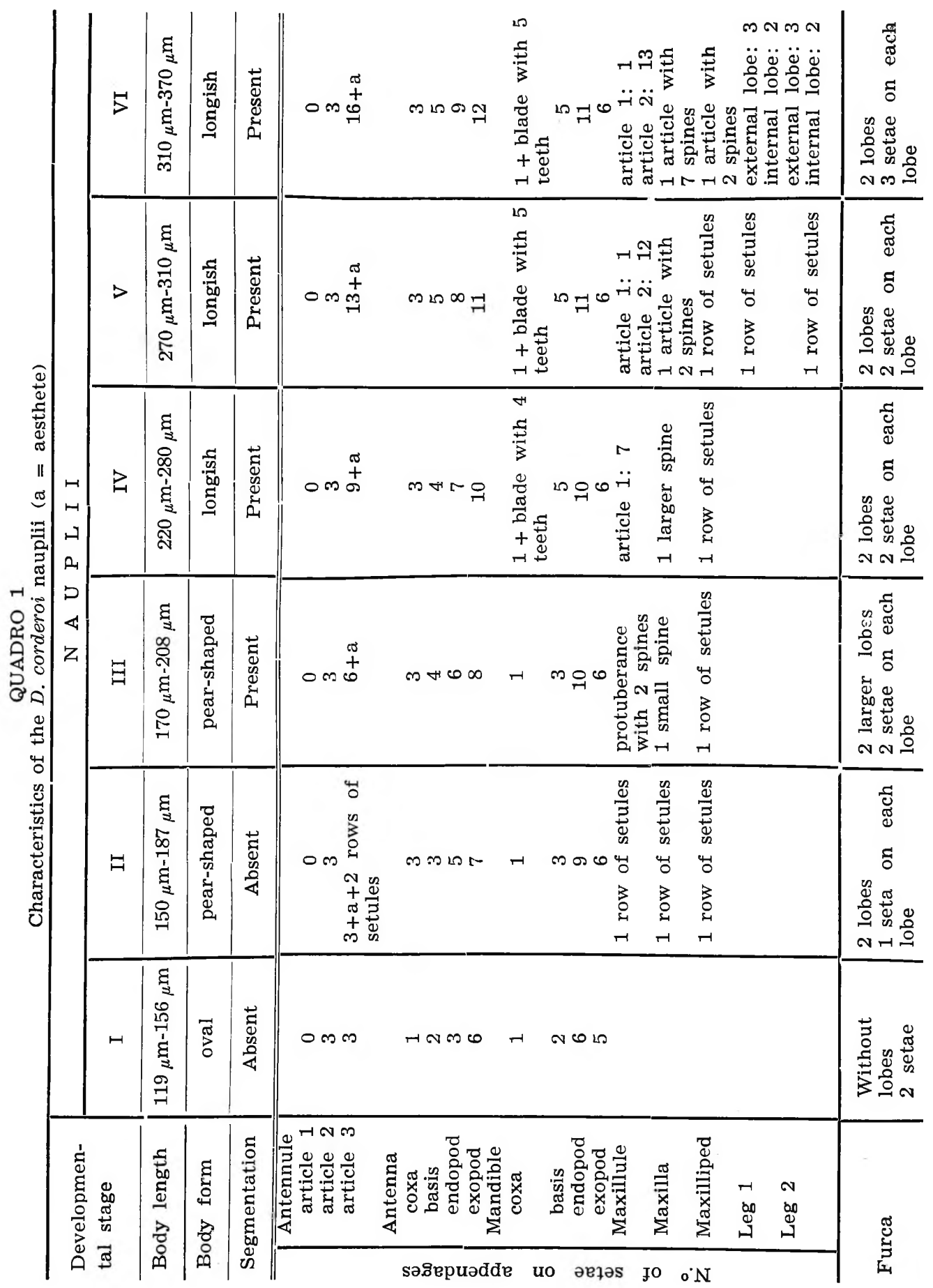




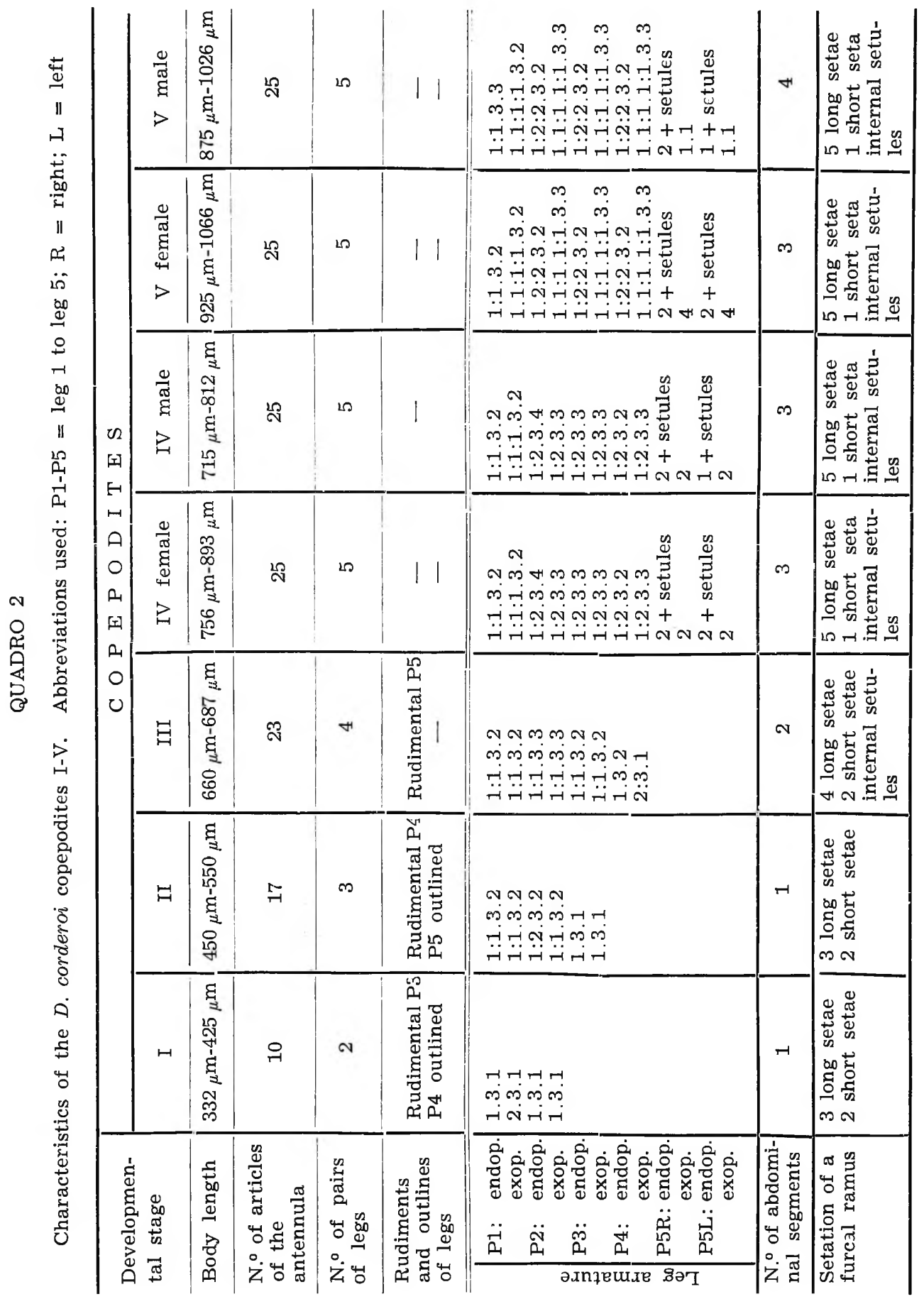




\section{REFERÊNCIAS BIBLIOGRĀFICAS}

BREHM, V (1933 a) - Mitteilungen von der Wallacea Expedition Woltereck: Mitteilung VI - Zool. Anz. Bd. 104:77-90.

(1933 b) - Mitteilungen von der Wallacea Expedition Woltereck. Mitteilung VII. Zool. Anz. Bd. 104:130-142.

(1933 c) - Diaptomus Thomseni nov-spec., ein merkwürdiger neuer Diaptomus aus Uruguay. Zool. Anz. Bd. 104:221-228.

(1933 d) - Zugleich ein Beitrag zur Systematik der südamerikanischen Diaptomiden. Zool. Anz. Bd. 104:283-288.

(1933 e) - Mitteilungen von der Wallacea Expedition Woltereck Mitteilung IV. Zool. Anz. Bd. 104:295-304.

COMITA, G. W. \& TOMMERDAHL, D. M. (1860) - The post embryonic developmental instars of Diaptomus siciloides Lilljeborg. J. of Morph. 107:297-355.

DIETRICH, W. (1915) - Die Metamorphose der freilebenden Süsswasser Copepoden. Zeitsch. wiss. Zool. Band. 113:252-324.

DUSSART, B. (1967) - Les copépodes des eaux continentales d'Europe occidentale. Tome I: Calanoides et Harpacticoides. Ed. N. Boubée \& Cia., Paris.

GURNEY, R. (1931) - British Fresh-Water Copepoda. Vol. I. The Ray Society, Séries n. ${ }^{\circ}$ 118:LII + 238 pp.

HANAOKA, T. (1952) - Study on free-living Copepoda nauplius. Bulletin of Naikai Regional Fisheries Research Laboratory.

KAMAL, A. \& ARMITAGE, K. B. (1967) - External morphology of adult and copepodid stages of Diaptomus clavipes Schacht 1897 - The University of Kansas. Science Bulletin, Vol. XLVII, pages 559-573.

KIEFER, F. (1932) - Versuch eines Systems der Diaptomiden (Cop. Cal.). Zool. Jahrb., Bd. 63, Jena.

Bd. 65, Jena.

(1968) - Versuch einer Revision der Gattung Eudiaptomus Kiefer (Copepoda Calanoida). Mem. Inst. Ital. Idrobiol., 24:9-160.

LIGHT, S. F. (1938) - New subgenera and species of diaptomid copepods from the inland waters of California and Nevada. Univ. California Berkeley Publs. Zool. 43:67-78.

(1939) - New American subgenera of Diaptomus Westwood (Copepoda, Calanoida). Trans. Am. Microscop. Soc., 58:473-484.

MARQUES, E. (1966) - Tropodiaptomus kieferi n.sp., Copépode Diaptomideo novo de água doce de Angola. Garcia de Orta (Lisboa) 14(2):181-186.

MARSH, C. D. (1913) - Report on freshwater Copepoda from Panama, with descriptions of new species. Smithsonian Inst. Publs. Misc. Collections, 61(3): 1-31.

(1915) - A new crustacean, Diaptomus verginiensis and a description of D. tyrelli Poppe. Proc. U. S. Natl. Museum, 49:457-462. 
- (1919) - Report on a collection of Copepoda made in Honduras by F. J. Dyer. Proc. U. S. Natl. Mus., 55:545-548.

(1929) - Distribution and key of the North American copepods of the genus Diaptomus with the description of a new species. Proc. $U$. $S$. Natl. Museum, 75, art 14:1-27.

OSORIO TAFALL, B. F. (1942) - Diaptomus (Microdiaptomus) cokeri, nuevos subgenero y especie de Diaptomido de las cuevas de la region de Valles (San Luis Potosi, Mexico) (Coped., Calan.). Ciência (Mex.), 3:206-210.

PEARSE, A. S. (1915) - An account of the Crustacea collected by the Walker Expedition to Santa Marta, Colombia. Proc. U. S. Nat. Mus. 49:531-556.

(1921) - Crustacea from Lake Valencia, Venezuela. Proc. U. S. Nat. Mus., 59:459-462.

PENNAK, R. W. (1953) - Fresh-Water Invertebrates of the United States. The Ronald Press Company, New York, IX + 769 pp.

TEISSIER, G. (1960) - Relative growth - in "The Physiology of Crustacea" Vol. I, Chapter 16, ed. by Talbot H. Waterman, 1960.

WILSON, C. B. (1932) - The copepods of the Woods Hole region Massachusetts. U. S. nat. Mus. Bull. 158:635 pp.

WILSON, M. S. (1954) -A new species of Diaptomus from Louisiania and Texas with notes on the sub genus Leptodiaptomus. Tulane Studies Zool. 2:49-60.

(1959) - Free-living Copepoda-Calanoida, p. 738-794 - in "Freeshwater biology" sec. ed. Ed. W T. Edmondson - New York - John Wiley \& Sons, Inc: $\mathrm{XX}+1248 \mathrm{pp}$.

WRIGHT, S. (1927) - A revision of the south american species of Diaptomus. Trans. Amer. Micr. Soc. 46(2):73-121 figs.

(1935 - Three new species of Diaptomus from Northeast Brazil. Ann. Acad. Bras. de Sc. $7(3): 213-233$ figs.

(1936) - Preliminary report on six new species of Diaptomus from Brazil. Ann. Acad. Bras. de Sc., 8(2):79-85 figs. 